\title{
Toma de decisiones laborales en la corte cuzqueña de los siglos XV y principios del XVI, según las tradiciones orales apuntadas por Juan de Betanzos ${ }^{1}$
}

\author{
Gabriela Sternfeld \\ Departamento de Estudios Españoles y Latinoamericanos \\ Universidad Hebrea de Jerusalén (Israel)
}

\section{INTRODUCCIÓN}

El tema que analizaré en este ensayo es la organización laboral y el tipo de relaciones laborales que se desarrollaron en el Estado Inca de los siglos XV-XVI.

Por tanto me interesa investigar el tipo de decisiones gubernamentales y el rango jerárquico de los que tomaron dichas decisiones en lo que hace a la organización laboral de tan vasto y complejo territorio.

Observé que en las tradiciones orales conservadas en la obra de Juan de Betanzos, "Suma y Narración de los Incas" de 1551, hay numerosos ejemplos en donde la corte cuzqueña toma decisiones gubernamentales de distinto tipo. Esto me llevó a intentar una reconstrucción del proceso específico para las mismas y en especial para las decisiones que se referían a las prestaciones laborales que el Estado Inca demandaba de los cientos de grupos étnicos que lo conformaron. De esta manera identifiqué a los actores que intervenían, el lugar físico en donde se desarrollaban, las atribuciones de los participantes, y el modo en que se llevaban a cabo dichas decisiones gubernamentales.

Lo que contiene la crónica "Suma y Narración de los Incas" son tradiciones orales andinas de origen cuzqueño (Cuzco fue la capital del Estado Inca). En especial informaciones provenientes de la familia real de Ynga Yupangue, ya que Juan de Betanzos estaba casado con una noble cuzqueña de esa familia y al hablar muy bien el quechua

1 Ponencia presentada en el IX Congreso de la Federación Internacional de Estudios de América Latina y el Caribe, Universidad de Tel Aviv, 12-15 de abril de 1999. 
(ejercía el cargo de intérprete oficial en la Audiencia cuzqueña desde1540), convivió y se relacionó con los parientes y conocidos de la misma. Por lo tanto, los informantes de nuestro cronista pertenecieron a la alta aristocracia inca, desempeñaron cargos claves en el gobierno y participaron activamente en los procesos de toma de decisiones.

Señalo el dato para hacer notar que es intención de estos informantes, resaltar, glorificar y dejar memoria de los hechos atribuidos a dicho linaje real en particular.

Sin embargo, mi propósito en este ensayo, es crear un modelo descriptivo de la toma de decisiones que hicieron a la organización laboral del Estado Inca, sobre la base de los ejemplos que nos brinda la crónica en cuestión y sobre la visión concreta de esa aristocracia cuzqueña a la que pertenecieron los informantes de Betanzos. Cabe resaltar sí, que la tradición de esta crónica es una entre varias otras tradiciones cuzqueñas. Y que a pesar de que la fuente se revele como parcial y pueda mentir en hechos concretos, lo importante para el análisis que propongo es que fueron informaciones de un grupo de la aristocracia cuzqueña y que el esquema que presentan sus descripciones, a pesar de interesado y "bien pulido" debió ser un esquema bien conocido entre los demás miembros de esa misma aristocracia cuzqueña.

Debo señalar que la selección de la crónica de Betanzos para analizar el proceso de toma de decisiones laborales en la corte cuzqueña, no significa que otras fuentes no mencionen tales procesos decisivos ; si no que, los descritos por Betanzos tienen ciertas ventajas, a saber: son descripciones muy tempranas, directas de la aristocracia cuzqueña y por último, el texto abunda en ejemplos. De manera que, otras fuentes las utilizaré para verificar en un futuro el modelo construido con los datos de la crónica de Betanzos.

Otra ventaja a tener en cuenta, es, que en el caso de la crónica de Juan de Betanzos, el problema de la filiación de las fuentes se reduce a poder determinar qué tradiciones escuchó, descartando prácticamente la posibilidades de pensar que éste pudo haber copiado otras fuentes escritas. Debido al muy buen manejo del idioma quechua del autor, podemos especular que los procesos descriptos son bastante completos y exhaustivos. En el caso de cronistas posteriores (por ej. Martín de Murua, Don Phelipe Guaman Poma de Ayala, Pedro Sarmiento de Gamboa), la filiación de fuentes exige un análisis mucho más complejo y a veces sin conclusiones claras. El único cronista contemporáneo a Betanzos fue Pedro Cieza de León, pero el problema radica en su falta de conocimiento del quechua en forma fluida, sumándose así la intermediación del los intérpretes; por otro lado no convivió con la aristocracia cuzqueña como en el caso referido de Betanzos (Domínguez Faura 1998: 212). 
Encuentro así un protocolo minucioso de procedimientos en la toma de decisiones que se repiten a lo largo del texto, lo que me lleva a sostener que, según el punto de vista de los informantes del cronista, se trató de instituciones cuzqueñas que funcionaron (permanente o creadas según las necesidades), y no meramente de recuerdos de decisiones importantes que la tradición oral conservó.

Constaté que hubo un ámbito institucional y físico en donde se decidían las cuestiones de estado, pero en la crónica no se le da un nombre específico. Cuando el Inca quería decidir algo llamaba a "su junta", a "su acuerdo", a "su consulta". Debido a esta imprecisión de los informantes de Betanzos, denominaré a estos ámbitos de decisiones con el nombre de asambleas.

Con respecto a las asambleas, hay numerosas y encendidas controversias entre los especialistas andinos que niegan la existencia de una institución de esta naturaleza en el Estado Inca.

Es esta la opinión de Demetrio Ramos (1987: LXXII), que sostiene que Betanzos comprendió equivocadamente a sus informantes y "tradujo" las reuniones entre el Inca y los "caciques provincianos" (la aristocracia provinciana), como un "reflejo mental de las Cortes de Castilla" o como un "remedo de Cortes", es decir fue una invención del cronista y no parte de la tradición oral.

También es la opinión de Martti Pärssinen. Paso a citar a este último autor:

"The Myth of the Inca Council.

The Inca king of the state was undoubtedly the supreme leader of the whole empire. On the other hand, according to many scholars, the Inca had appointed four apos (apocuna in plural) to the leadership of four suyus of the Inca realm who, together with the Inca King, formed the Supreme Council of Tawntinsuyu. [Karsten 1946:122, 123-124; Rowe 1946:263; Moore 1958:66, 111-112; Mason 1978:178].

However, we know extremely little about these supreme apos or more correctly, capac apos. Also, the information about the Supreme Council is extremely contradictory, and what the chroniclers tell about it sounds like the Supreme Council of Spanish Indies which resided in $16^{\text {th }}$ century Spain.

Some early sources like Quipocamayos, Las Casas, Cieza, Betanzos or Sarmiento, do not mention the Supreme Council as a special fixed institution although some of them actually speack about the Inca"s advisors and even about "governors" of the suyus.

The most common sources which mention the Council of four capac apos are Falcón, Murúa, Garcilaso and Cobo. [Falcón (1567) 1918:146; Murúa 1616: lib. Li, caps.ii.vii; 1987: 346, 360; Garcilaso 1609: lib. ii, cap. Xv; 1976: 93; Cobo 1653: lib. 12, cap. xxv, 1964:114].

(...) our sources are extremely contradictory. Local sources do not mention the Supreme Council either, which is amazing if it was an important institution of the Inca realm. 
(...) In general, it seems that the idea of a Supreme Council is too European to have been a real one. Probably MURRA is correct when he advised us to leave the whole idea as a invention of some chroniclers. [John V. MURRA (personal communication)]". (Pärssinen 1992: 257-259)

Resumiendo, las críticas que estos especialistas sostienen para negar la existencia de las asambleas son las siguientes:

- Hay contradicciones en las pocas informaciones de que disponemos.

- Tal institución como la presentan los cronistas se parece demasiado, y por tanto sería una extrapolación de instituciones españolas del siglo XVI, como el Consejo Supremo de Indias o las Cortes de Castilla.

- No existe confirmación en las fuentes locales andinas de tal institución.

$\mathrm{Si}$ bien es cierto que los informantes de Betanzos no llamaron con un nombre específico a la institución que tomaba decisiones en la corte cuzqueña, también es cierto que nos dieron los suficientes ejemplos de reuniones de ese carácter, como para poder analizar su procedimiento, sus atribuciones y sus participantes.

Cuando analicé los datos contenidos en los ejemplos de tales reuniones, encontré modalidades de decisiones, formas de acción, tipos de planificación y ejecución que difieren notablemente de las instituciones españolas del siglo XVI, más bien "suenan" propiamente andinas.

Por otro lado no toda información o institución que se parece a algo español, deja de ser andina o inca per se. Como ya lo ha demostrado Jan Szemiński (1998), este postulado utilizado por algunos investigadores, para la crítica de las fuentes, no es un criterio suficiente para descartar de por sí informaciones contenidas en las crónicas de la tradición oral andina.

"Si el sol luce para todos y su representación no puede ser diagnóstica de lo andino, entonces $\underline{\mathbf{l o}}$ similar a lo español puede ser andino. (Szemiñskij 1998:1-3). [El subrayado pertenece al autor de la cita].

Por tanto el mismo hecho de que se mencione un consejo o asamblea no es prueba de su origen español o andino. Lo que me lleva a intentar buscar otros criterios más útiles para la investigación histórica. Como por ejemplo especificar los componentes, estructura y modalidad de dichas asambleas, así como las reglas de reclutamiento de los participantes. Así mismo, creo, que la indefinición de los informantes de Betanzos, con respecto a darle nombre a dicha institución e incluso la identidad específica de los participantes en la misma, fuera del Inca reinante y algunos hermanos y parientes muy 
cercanos, es una indefinición que intenta resaltar puramente los hechos de un particular linaje real (panaka) contenidos en los cantares y cuentos de la familia real de Ynga Yupangue (parientes de los informantes y del mismo Betanzos) y no los hechos y participación de otros linajes cuzqueños.

Pero a pesar de tales intenciones, vemos que el Inca y su linaje permanentemente a lo largo del texto, consultaban, negociaban y acordaban con otros señores de la aristocracia cuzqueña y con señores de las aristocracias provincianas, en el ámbito de las asambleas.

Para finalizar y en contraste con las críticas y recomendaciones de Ramos, Pärssinen y Murra, creo posible presentar en este trabajo un modelo descriptivo del proceso de toma de decisiones de la organización laboral en la corte cuzqueña, según las tradiciones orales conservadas en la crónica de Betanzos.

\section{MODELO DESCRIPTIVO DEL PROCESO DE TOMA DE DECISIONES LABO- RALES EN LA CORTE CUZQUEÑA}

Cada vez que en la crónica de Betanzos el Inca reinante "proponía" una tarea estatal, una construcción, una reforma religiosa, una prescripción ritual, sucesión real, acuerdo político, o campaña militar, estos acontecimientos son relatados de acuerdo al siguiente patrón:

- preparación de la tarea

- desarrollo de la tarea

- finalización de la tarea.

Observé que cada realización o proyecto del gobierno cuzqueño involucraba procesos de decisión. Analicé setenta y ocho de estos procesos decisivos. Los separé por temas y obtuve cinco diferentes grupos temáticos en los cuales las autoridades Incas decidian posiciones a adoptar o tareas que efectuar:

A) Establecimiento y renegociación de relaciones políticas. (22 ejemplos).

B) Campañas militares de defensa o expansión. (19 ejemplos).

C) Construcción de infraestructura económica, asignación de contribuciones estatales. (15 ejemplos).

D) Establecimiento de leyes, prescripciones rituales, reformas religiosas. (11 ejemplos).

E) Sucesiones y coronaciones del Inca. (15 ejemplos). 
Lo más interesante al internarme en el análisis de estos cinco grupos temáticos, fue detectar que lo que describen las tradiciones orales en la crónica de Betanzos, son dos fenómenos sociales bien concretos y de reciente interés por parte de los investigadores andinos, a saber: las negociaciones y acuerdos entre los grupos involucrados en dichos procesos de toma de decisiones y el consenso como modalidad de los mismos.

Los acuerdos y negociaciones que yo clasifiqué dentro de los grupos temáticos D (Establecimiento de leyes, prescripciones rituales, reformas religiosas) y E (Sucesiones y coronaciones del Inca), están brillantemente investigados y analizados en una obra reciente, del historiador polaco Mariusz Ziółkowski (1996), llamada "La guerra de los Wawqi. Los objetivos y los mecanismos de la rivalidad dentro de la élite Inca, $S$. XV-XVI".

Yo me dediqué especialmente a analizar los acuerdos y negociaciones que se daban en el ámbito de las prestaciones laborales que el Estado Inca demandaba para la realización de toda empresa estatal y del establecimiento de relaciones laborales para futuras tareas estatales.

Como es bien sabido, el Estado Inca requería de las provincias bajo su dominio un tributo en trabajo, esto es, no extraía de las economías étnicas locales y de las familias aldeanas bienes producidos en dichos circuitos, sino que exigía un tributo en prestaciones, que era el trabajo entregado por la población en forma de servicios realizados para el Estado. Cumpliendo con el principio de relaciones recíprocas en los Andes el Estado Inca exigia trabajo, pero se hacía cargo del sustento, vestimenta, herramientas, fibra, materiales, que los trabajadores de las provincias utilizaban cuando realizaban una tarea estatal (Betanzos 1987:60/1 [1551: I, cap. XIII]; Sternfeld 1998: 3).

Llamo empresa estatal a cualquier tarea de construcción de depósitos, caminos y puentes viales, reparto de tierras, acuerdo político, reedificación del Cuzco, acondicionamiento agrícola o campaña militar que el Inca "proponía", e involucraba el ruego o petición de la fuerza de trabajo por parte de la autoridad estatal, la realización de la misma y la consiguiente redistribución de bienes y mercedes prestigiosas en retribución a las autoridades de los grupos que brindaron el apoyo laboral (Grupos temáticos A, B y C como está referido más arriba. En el Anexo de este ensayo se podrán leer en detalle los ejemplos de dichos grupos temáticos).

Las negociaciones y acuerdos en las prestaciones laborables se llevaban a cabo entre distintos niveles jerárquicos de autoridades del Estado Inca: desde el Inca (representante supremo en la jerarquía social), los "Señores del Cuzco" y los orejones 
gobernadores provinciales (representantes de la aristocracia cuzqueña), los "caciques" señores de las provincias y los "principales" (representantes de la aristocracia provinciana), hasta el nivel jerárquico inferior mencionado en la crónica, representado por los "mayordomos" de las aldeas provincianas (llaqta kamayuq).

Estas observaciones con respecto a la obra de Betanzos, concuerdan con las opiniones de algunos investigadores andinos (Pease 1992: 30/31; Ziółkowski 1996: 238), en donde la imagen de un Tahuantinsuyu omnipotente y totalitario pierde consistencia, y se revela más bien en sentido dinámico e interelacionado con los distintos poderes y autoridades locales que lo conformaron.

Con respecto al consenso de los participantes en las asambleas, de los setenta y ocho casos que analicé en por lo menos 55 ejemplos, el consenso unánime de los participantes es explícito, en 5 casos se explicita que no se llegó a un consenso unánime, y en los 18 restantes el consenso unánime de los participantes no está relevado por la tradición oral conservada en la crónica de Betanzos.

Siguiendo con el análisis de los tres grupos temáticos que denominé A, B y C, en donde las autoridades incas tomaban decisiones en el ámbito de las prestaciones laborales observé que en los 57 casos que investigué (recuérdese que no tomé en cuenta los grupos D y E), había rasgos comunes y momentos claves que se repetían en los mismos, lo que me llevó a compararlos entre sí. Con la repetición y sucesión ordenada de estos momentos claves, construí un modelo descriptivo del proceso de toma de decisiones laborales en la corte cuzqueña, según las tradiciones orales de la crónica de Betanzos.

Cuando digo que trabajé con 57 ejemplos de la crónica, no quiero decir que en los 57 ejemplos se dan todos los momentos claves y en un mismo orden. Hay ejemplos en donde algunos momentos claves no están especificados o el orden está levemente alterado. También observé que hay un cambio de frecuencia, que va disminuyendo a medida que avanzamos en la lectura de la crónica, en la aparición de estos momentos claves. Lo que me llevó a preguntar si esa disminución en la mención y descripción de los momentos involucrados era una transformación en la institución de las asambleas, o más bien se trataba de que, ya sea los informantes y/o el cronista se cansaron de contar el proceso cada vezy lo dieron por supuesto y explicado en los casos anteriores, sobre todo en los ejemplos referidos al reinado de Ynga Yupangue. Me inclino a pensar que se trata de esta segunda posibilidad, ya que de hecho en la crónica hay un ejemplo de asamblea hasta en el reinado de Mango Ynga en época colonial. 
El modelo descriptivo que elaboré contiene 15 momentos claves, que paso a enumerar:

1. El Inca "se proponía" una tarea según información que disponía de antemano.

2. El Inca invitaba a los "Señores del Cuzco" a reunirse con él en una fecha estipulada y en un espacio físico estipulado.

3. El Inca recibía a los "Señores del Cuzco" y éstos le hacían su "acatamiento". (Entraban en la asamblea).

4. El Inca exponía las características de la empresa a realizar y el tipo de prestaciones laborales que involucraba dicha tarea.

5. Los "Señores del Cuzco" pedían especificaciones sobre la tarea.

6. Se planificaba el desarrollo de la tarea.

7. Los "Señores del Cuzco" y el Inca acordaban en la realización de la tarea.

8. Los "Señores del Cuzco" enviaban mensajeros a las autoridades provinciales en demanda de las prestaciones de fuerza de trabajo requeridas, estipulando la fecha de reunión en el Cuzco. (Salían de la asamblea).

9. En la fecha estipulada el Inca invitaba a todos los "caciques y señores provinciales" ante su presencia, y junto con los "Señores del Cuzco" se los agasajaba. (Entraban en la asamblea).

10. Los "caciques provinciales" realizaban su acatamiento, sacrificios y ofrendas al Inca.

11. El Inca les anunciaba la tarea a realizar. Ellos concordaban en realizarla unánimemente.

12. Los "Señores del Cuzco" junto con los "caciques provinciales" decidían el reparto de las cargas y obligaciones de cada grupo étnico en particular. (Salían de la asamblea).

13. Se realizaba la tarea estatal.

14. Una vez concluida la faena, el Inca se reunía nuevamente con todos los "Señores del Cuzco" y los "caciques provincianos" y ofrecía una fiesta de agradecimiento y despedida por haber contribuido a la misma, les entregaba regalos y mercedes prestigiosos. (Entraban en la asamblea).

15. Los "caciques provinciales" y los "Señores del Cuzco" hacían su acatamiento al Inca, se despedian y regresaban a sus tierras y aposentos a "descansar". (Salían de la asamblea).

Una vez que identifiqué por lo menos 15 momentos claves en los ejemplos consi- 
derados de procesos de toma de decisión laborales, los agrupé en tres etapas de la siguiente manera:

- Etapa de toma de decisiones y planeamientos para la realización de una tarea estatal. (Incluye los momentos claves del modelo descriptivo 1 al 8).

- Etapa de evaluación de las fuerzas laborales disponibles, reparto de contribuciones y realización de la tarea estatal. (Incluye los momentos claves del modelo descriptivo 9 al 13).

- Etapa de finalización de la tarea estatal con las consiguientes fiestas, sacrificios, ceremonias rituales y reparto de regalos y mercedes. (Incluye los momentos claves del modelo descriptivo 14 y 15 ).

Las tres etapas aquí enumeradas y en ese orden sí aparecen en los ejemplos considerados.

En el siguiente apartado ejemplificaré y analizaré las huellas en la tradición oral de las negociaciones, acuerdos y consensos en lo que se refiere a las prestaciones de fuerza laborable en las tres etapas enumeradas.

\section{ETAPAS DEL MODELO DESCRIPTIVO DEL PROCESO DE TOMA DE DECISIONES LABORALES EN LA CORTE CUZQUEÑA}

Quiero hacer algunas aclaraciones antes de comenzar el presente apartado. En general este trabajo contiene abundantes y a veces extensas citas. No quiero disculparme por ello, sino por el contrario hacer notar la importancia metodológica de las mismas. Este intenta ser un ensayo de etnohistoria andina, vale decir en donde se preferencia y se intenta por todos los medios rescatar y escuchar "la voz" de la tradición oral antigua. Es bien conocido el obstáculo metodológico de las distintas mediaciones, como lo son los informantes tardíos, los traductores, y los escribanos. En el caso particular de la crónica de Betanzos, el cronista no vivió las experiencias que relata, pero le fueron contadas por informantes tempranos en la propia lengua indígena, personas que durante el Estado Inca fueron adultas, tuvieron importantes cargos políticos y se educaron bajo una ideología puramente andina. Por eso es mi intención que se les "escuche" y disfrute como yo lo hice.

En todas las citas cuando quise resaltar algo en especial lo señalé con negritas, y cuando agregué alguna aclaración pertinente utilicé corchetes.

Por último, en las citas y en mi texto los nombres de los Incas tratados son los que aparecen textualmente en la crónica de Betanzos, respetando la "voz" de los informan- 
tes. En cuanto a la denominación de las aristocracias cuzqueñas y provincianas utilicé el mismo criterio, si bien la tradición oral denominó a estos sectores de poder de varias maneras, elegí una denominación para cada grupo para hacer más sencilla la lectura del ensayo, a saber: "Señores del Cuzco" y "caciques provincianos".

\subsection{ETAPA DE TOMA DE DECISIONES Y PLANEAMIENTOS PARA LA REALIZACIÓN DE UNA TAREA ESTATAL. (INCLUYE LOS MOMENTOS CLAVES DEL MODELO DESCRIPTIVO 1 Al 8).}

El Estado Inca se caracterizó por la precisión y dedicación en el manejo racional de los muy variados y complejos recursos naturales y sociales de que dispuso para la creación de una economía agropecuaria eficiente y de vastas magnitudes (Earls 1976, 1986, 1991).

Precisamente una de sus herramientas fundamentales fue el circuito informativo con que contó para manejar dichos recursos. Por un lado, estaba le infraestructura material de dicho circuito, comprendida por los caminos costeños y serranos, puentes y postas de correos, que se esparcían por todo el Estado (una infraestructura de tal naturaleza y magnitud no existió en los siglos XV-XVI en otras partes). Además existían una serie de instituciones estatales específicas que eran las encargadas de generar y transmitir las informaciones del circuito, como lo fueron los gobernadores y burócratas provinciales, el servicio de mensajeros entre postas (corredores muy bien entrenados), los inspectores estatales, los espías y la policía secreta. Para la inteligibilidad de la información y la transmisión dentro del circuito informativo, el Estado Inca se valió de la utilización de lenguas francas o generales como lo fueron algunos dialectos del quechua o el aymara. Por último, para la conservación y reutilización de las informaciones transmitidas en el circuito estatal, empleó el sistema contable de khipu.

Vale decir, el manejo racional del Estado Inca se basaba en un circuito informativo eficaz, estable, confiable y rápido, por donde fluían distintas categorías de informaciones, por un lado informaciones inmediatas y telegráficas como por ejemplo de rebeliones, catástrofes naturales, o buenas cosechas, por el otro, informaciones periódicas, con datos poblacionales, reservas, estado de situación de las provincias, experimentos agropecuarios, migraciones. El circuito informativo aquí descripto permitió al Estado Inca tomar decisiones concretas y conformes a los datos recabados, como así mismo armar planes de acción adecuados a las posibilidades de la situación. Veamos un ejemplo que nos brinda la crónica de Betanzos: 


\begin{abstract}
"e pasado este tiempo de los veinte años tuvo nueva [Ynga Yupangue] que delante de Laracache que es veintidos leguas del Cuzco hacia la provincia de los Charcas habia una provincia y pueblo que se decia Hatun Colla y que en ella había un señor que se decía Ruquicapana al cual pueblo de Hatun Colla y señor ya nombrado eran sujetos y a él obedientes otros muy muchos señores que en torno de su pueblo eran a veinte leguas y a veinticinco y que ansi mismo se nombraba Capac capaapoyndichori que dice rey y solo señor hijo del sol y que era muy poderoso y que tenía gran poder de gente y que la tal gente era muy guerrera y belicosa y como él tuviese esta nueva holgóse mucho porque lo que él deseaba era ver que en su tiempo hubiese otro señor que tuviese la presunción del para irse a ver con él y con el tal probar sus fuerzas y poder y como él tuviese esta nueva después de haber pensado lo que en la tal jornada pensaba hacer mandó que todos los señores del Cuzco se juntasen en su casa un cierto día porque tenía con ellos ciertas cosas que comunicar..." (Betanzos 1987: 100 [1551: L I, cap. XX]).
\end{abstract}

Si consideramos en la cita precedente las informaciones indudablemente provenientes de la tradición oral, como lo son los nombres propios y el texto quechua, y descartamos las explicaciones o comentarios de Betanzos (aclaración de la localización de Laracache y la traducción del texto quechua), vemos el tipo de información con que el Inca ya contaba cuando llamaba a reunirse en la asamblea: existía el pueblo de Hatun Colla un señor lo suficientemente poderoso y con aspiraciones políticas y religiosas tales (rey, señor único supremo, hijo del sol) como para que el Inca quisiera probar su propia fuerza y poderío guerrero. Basándose en ello, el circuito informativo brindará información detallada sobre la capacidad y calidad bélica del enemigo.

Era tan importante el buen funcionamiento de este circuito informativo que los infractores a dicho circuito eran severamente castigados con un sistema punitivo también bien específico (Betanzos 1987:113 [1551: L I, cap. XXII]).

El pedido de ayuda laboral para la realización de una tarea "comenzaba" con la invitación de los "Señores del Cuzco" y/o de los "caciques provincianos" a los aposentos o casas del Inca, en una fecha determinada.

Cuando la tradición oral deja constancia del lugar de reunión de las asambleas, en los ejemplos considerados, el lugar físico son los aposentos del Inca o en su defecto en los aposentos de los que "invitan" a la asamblea. En otros casos la plaza central del Cuzco.

"e como viese [Ynga Yupangue] que el edificio y reparación de las tales tierras iba a la larga y que según iban los reparos que los tales hacían [los señores del Cuzco en las tierras designadas a cada uno] y que era edificio que no se podría acabar tan ayna mandó que los señores e caciques que allí eran se juntasen en su casa cierto día y luego fueron juntos bien ansi como él 
lo mandó y siendo allí en sus casas dijoles que había gran necesidad que en la ciudad del cuzco hubiese depósitos de todas comidas ansi de maiz como de ají e frijoles e chochos e chuño e quinua e carnes secas e todos los demás proveimientos e comidas curadas que ellos tienen... Ynga Yupangue mandó luego a aquellos señores del Cuzco que proveyesen allá en sus posadas juntamente con aquellos caciques los orejones que ansi habían de ir por los pueblos e provincias a juntar e traer las tales comidas e mantenimientos...y ansi fueron los señores a sus posadas y hicieron allá su junta ellos e los caciques e repartieron lo que cada provincia había de traer e contribuir..." (Betanzos 1987: 56/7 [1551: L I, cap. XII]).

El lugar de reunión de las asambleas de autoridades, como lo muestra la tradición oral en la cita que antecede, correspondía a los aposentos de los anfitriones, es decir a los interesados en recibir la prestación laboral. Por tanto debían brindar y obsequiar hospitalidad en sus propias casas para luego "pedir" el apoyo a las provincias.

Además la fijación de una fecha determinada para la reunión en los aposentos de los que invitan nos da la pauta de la utilización de un calendario común a todo el territorio del Estado (Betanzos 1987: 87 [1551: L I, cap. XVIII]; 1987: 100 [1551: L I, cap. XX]).

En cuanto a la identidad de los participantes en dichas asambleas, como ya anticipé en la Introducción de este trabajo, la información es calculadamente reservada, ya que el interés de los informantes y del propio cronista es resaltar los hechos de la familia real de Ynga Yupangue.

A pesar de ello, los que siempre y en toda decisión estaban presentes junto al Inca, son los "Señores del Cuzco" pertenecientes a su familia pero también a otras familias y linajes reales (ayllus cuzqueños reales y no reales de orejones).

Numerosos trabajos eruditos y entre ellos los de Tom Zuidema se han escrito sobre la organización social y jerárquica del Cuzco, no es intención de este trabajo discutir dicho intrincado tema, sino mas bien analizar qué funciones les asignaban la tradición oral aquí analizada, y qué número de grupos sociales cuzqueños representaron.

Pienso que es importante el criterio del número de participantes dentro de las asambleas, ya que el consenso requerido para tomar decisiones laborales no podría haberse llevado a cabo si estos "señores" hubiesen sido demasiados y tampoco muy pocos. Las negociaciones eran llevadas a cabo por los jefes o cabezas de linajes. Daré dos ejemplos que nos brinda la crónica de Betanzos con respecto a estos "Señores del Cuzco". 
[Se refiere a la construcción y sacralización del Usnu solar, obelisco de piedra que representó a la divinidad solar, en la plaza del Cuzco] "al poner que la piedra se puso en medio de la plaza del Cuzco hízose en ella un gran hoyo primero donde todos los de la ciudad chicos y grandes ofrecieron al sol las piezas de oro que les paresció y esto ofrecido cerraron el hoyo encima del cual hicieron y edificaron una pila de cantería de altor de medio estado y en la redondez de la pila enterraron unos bultos de oro de largor de un dedo y del mismo gordor cada uno y estos bulticos que ansi enterraron en torno de la pila antes que los metiesen debajo de tierra hicieron dellos tantos escuadroncitos cuantos linajes había en la ciudad del cuzco y con cada linaje un bulticos de aquellos que significasen el más principal de cada linaje de aquellos y estos escuadrones...y este meter de estos bulticos ansi entorno della era un ofrescimiento que hacían al sol de la generación de los del Cuzco y de los linajes della desde que Mango Capa la habia poblado hasta los que en aquel tiempo eran y puesta la piedra y los bulticos en la manera que habeis oído todos los de la ciudad le hicieron sacrificios..." (Betanzos 1987: 53 [1551: L I, cap. XI]).

La cita menciona que había linajes de la aristocracia inca desde los tiempos de la fundación de la ciudad, en esta tradición oral, dicha fundación atribuida a Mango Capac. Cada linaje en particular fue representado por la ofrenda de un bulto pequeño de oro, pero es importante señalar, la existencia de los "principales" de cada linaje cuzqueño, también detallada en dicha ofrenda a la divinidad solar. Vale decir, hubo diversos linajes cuzqueños y en ellos una jerarquía máxima representada por estos "principales", lo que me lleva a identificar esta jerarquía máxima dentro de los linajes cuzqueños con los "Señores del Cuzco" de las asambleas.

En la cita que sigue a continuación, los informantes de Betanzos nos dan la pauta del número de estos "Señores del Cuzco", ya que nos informan del casamiento del Inca con "otras veinte señoras hijas de aquellos principales de la ciudad". Lo interesante es que hicieron hincapié en que tomó por mujeres tanto de los linajes de Hanan Cuzco como de Hurin Cuzco, es decir de todos los linajes cuzqueños.

El número de veinte "Señores del Cuzco" con vozy voto en las asambleas me parece algo que pudo ser "manejable" por parte del Inca, desde el punto de vista de los acuerdos a los que tenía que llegar con ellos, como veremos más adelante en este ensayo.

[Luego de la conquista de los Soras, Ynga Yupangue queda en la ciudad del Cuzco ] "en este tiempo hubo en su mujer la que él tomara cuando tomó la borla dos hijos y al primero llamó Yamque Yupangue y al segundo Topa Ynga Yupangue y otro ansi mismo había habido en otras de sus mujeres al cual nombraron Capac Yupangue en el nacimiento de los cuales y de cada uno dellos hizo grandes fiestas y regocijos y sacrificios y ansi mismo en este tiempo tomó por mujeres otras veinte señoras hijas de aquellos principales de la ciudad ansi de los de 
Huren Cuzco como los de Hanan Cuzco que dice el Cuzco abajo y el Cuzco arriba..." (Betanzos 1987: 99/100 [1551: L I, cap. XX]).

Una vez que los "Señores del Cuzco" y/o los "caciques provincianos" se presentaban ante el Inca como sus invitados, realizaban el "acto del acatamiento". Esto es, cualquier encuentro con el Inca revestía un momento ideológicamente fuerte, festivo y ritualizado, que significaba honrar a la jerarquía social mayor del Estado además de la divinidad, ya que éste como hijo del Sol, la personificaba. Los "señores" le entregaban los presentes que traían y le hacían sacrificios por ser un ser sagrado (waka).

"e llegados que fueron [los caciques provincianos] a la ciudad del Cuzco hicieron su acatamiento al Ynga en esta manera porque ésta era la usanza que se tenía cuando delante se vían que como delante del fuesen alzaban las manos e rostros al sol haciéndoles sus mochas e acatamiento e luego ansi mismo las hacían al Ynga ni más ni menos y las palabras que ansi le decían cuando ansi le saludaban eran que le decían: Ah hijo del Sol amoroso e amigable a los pobres esto hecho poníanle delante sus presentes que ansi le traían e luego le sacrificaban ciertas ovejas e corderos delante del con todo el respeto e acatamiento como a hijo del sol y esto ansi hecho el Ynga los saludaba diciendo que fuesen bienvenidos e preguntándoles si venían buenos e si lo estaban ansi mismo en sus tierras..." (Betanzos 1987: 59/60 [1551: L I, cap. XIII]).

"llegáronse a él todos juntos [los señores del Cuzco ante Guayna Capac] y después de le haber hecho el acatamiento y ofrecídole los dones que llevaban porque habrán de saber que Ynga Yupangue puso una constitución que ninguno por señor o señora que fuese no paresciese ante el señor con las manos vacías si no que cada vez que fuesen a le hacer acatamiento y verle 0 negociar con él algo que llevasen en las manos o alguna cosa que le ofrescer aunque fuese fruta o verdura o flores o pájaros u otras cosas ansi y esto mismo se hace hoy en día entre los señores y señoras en la ciudad del Cuzco..." (Betanzos 1987: 193 [1551: L I, cap. XIVI]).

En las dos citas precedentes, la tradición oral deja constancia del respeto, formalidad y sacralidad que significaba el presentarse ante el Inca, y de hecho siempre había intercambio de saludos, sacrificios y circulación de bienes prestigiosos.

A continuación, cada uno tomaba el asiento que le correspondía como "señor" participante en las asambleas, y se pasaba a la discusión.

"Topa Ynga Yupangue dio e hizo merced a su sobrino que fuese proveedor mayor del Cuzco de todo el ganado que el Cuzco tenía en toda la tierra... y visto por Yamque Yupangue la merced que le hacía su tío Topa Ynga Yupangue levantóse de su silla y asiento que tenía de señor y fuese a su tío y besóle en el carrillo en señal de amor y agradecimiento por la merced que le hacia y esto hecho tornóse a sentar en su silla..." (Betanzos 1987: 176 [1551: L I, cap. XXXIX]). 
El asiento que correspondía a los "señores" que participaban en las asambleas, como consta en la cita anterior, nos confirma el origen andino de dicha institución. Según José Luis Martínez Cereceda, la silla de la cita corresponde a la "tiyana", uno de los atributos del poder y de las divinidades en las sociedades andinas. El asiento tenía un efecto diferenciador en los Andes: el simple acto de sentarse en una silla y no el suelo como el resto de las personas, denotaba status social superior, autoridad y ejercitación de un cargo (Martínez Cereceda: 1995: 69/79). Si todos en las asambleas tuvieron una tiyana, esto demuestra la alta jerarquía de estos "señores" (ya que se sentaban junto al Inca) y su carácter de waka (divinidad, sagrada). Este último aspecto no muy europeo.

Así mismo, en las asambleas participaban otros funcionarios y aristócratas cuzqueños, como mensajeros, militares o científicos que brindaban información a los que tenían voz, silla y voto, es decir a los "Señores del Cuzco" y al Inca (Betanzos 1987: 46 [1551: L I, cap. X]; 1987: 272 [1551: L II, cap. XXII]).

A continuación el Inca exponía las características de la tarea a emprender, la información disponible y el tipo de prestaciones laborales que se requerirían. En algunos ejemplos la tradición oral también deja constancia del pedido de especificaciones por parte de los señores presentes en las asambleas y luego se pasaba a planificar los pasos de la tarea y a designar a los responsables de la misma.

\footnotetext{
"Y ya que Ynga Yupangue se vido señor en la orden y manera que ya la tal historia os ha contado e que ya no tenía en que entender en edificio de la ciudad después de se haberse holgado con los suyos mandó que todos los señores del Cuzco y los demás caciques e principales se juntasen en la plaza los cuales ansi fueron juntos e siendo allí todos dijoles que él tenía noticia que en torno de aquella ciudad había mucha y muy gran cantidad de pueblos e provincias y para él que tenía fuerzas que era mal vivir con poco que tenía pensado y ordenado de se partir de aquella ciudad de alli en dos meses a buscar adquirir e sujetar los tales pueblos e provincias a la ciudad del Cuzco...para la cual jornada tenía necesidad de cien mil hombres de guerra que para aquellos dos meses se los tuviese juntos en aquella ciudad del Cuzco con sus armas y los demás proveimientos que necesarios les fuese para la tal jornada... mandándoles que en sus tierras dejasen todo recaudo de principales e mayordomos los cuales tuviesen cuidado de hacer sembrar muchas e muy grandes sementeras porque entendía que les sería menester según el tiempo que él tenía pensado de andar en la guerra..." (Betanzos 1987: 87/ 88 [1551:L I, cap. XVIII]).
}

En la cita precedente vemos que se planificaba la salida a la campaña militar, estipulando el tiempo de preparación y la cantidad de guerreros necesarios. Ahora bien, 
podemos preguntarnos qué significó el número "cien mil hombres de guerra" en ese contexto. Por un lado, reunir semejante fuerza en el Cuzco debió conllevar ciertos problemas logísticos no sencillos, por el otro, sabemos que en los estados europeos de los siglos XVI-XVII la movilización de soldados para el ataque, no fue un reclutamiento total de la población, sino un reclutamiento parcial: un soldado de cada diez unidades domésticas. Por el momento no sabemos cuál fue la tasa de reclutamiento empleada por el Estado Inca. Sin embargo, los números de 100.000 ó 50.000 son utilizados muy frecuentemente en la tradición oral. A lo mejor se trata de una manera de expresar cantidades muy grandes de soldados, pero también, existe la posibilidad de que esos números no expresen guerreros, sino rangos jerárquicos de autoridades andinas.

La organización de la tarea también incluía dejar estipulado y planificado el trabajo agrícola en las provincias, ya que se tenía en cuenta el tipo de aprovisionamientos y alimentos que se necesitarían, de acuerdo a la duración de dicha campaña y de acuerdo al calendario agrícola de siembras, cosechas y lluvias que había que coordinar con la salida de los campesinos/guerreros de las provincias (equilibrio de necesidades agrícolas estatales y provinciales, siempre delicado y complejo en el ecosistema andino).

Así como se planificaban los pasos a tener en cuenta, también se nombraban los responsables máximos de la tarea, en la cita que prosigue, la responsabilidad de una campaña militar a Collasuyu recayó en dos "hijos" del Inca y en otros seis "Señores del Cuzco":

[Ynga Yupangue] "mandó juntar a los suyos a los cuales como fuesen juntos djjoles lo que tenía ansi pensado y ordenado y como quería enviar sus hijos e algunos de ellos que fuesen y conquistasen por la provincia de Collasuyo los cuales dijeron que eran bien lo ansi por él acordado que ellos estaban prestos e obedientes para hacer lo que ansi les mandase y que nombrasen dellos los que habían de ir la tal jornada y los señores de sus hijos en cuya compañía ellos habían de ir y luego el Ynga dijo que los que habían de ir la tal jornada de sus hijos que era Amaro Topa Ynga y Paucar Usno y los que dellos habían de ir que habían de ser seis señores y luego allí los señaló de los que allí en la junta eran e ansi mesmo nombró el número de la gente que habían de llevar que fueron cien mil hombres de guerra los cincuenta mil habian de ser de la provincia de Collasuyo y los otros cincuenta de los demás pueblos e provincias..." (Betanzos 1987:119/120 [1551:L I, cap. XXIII]).

Prosiguiendo con los que denominé "momentos claves" de los procesos de decisión laboral en la corte cuzqueña, la tradición oral conservada en la obra de Betanzos deja constancia del consenso unánime de los participantes en las asambleas y éste fue un rasgo, a mi entender, fundamental y central de dicha institución. A continuación presento una pequeña cita que hace referencia a dicho fenómeno: 
"los cuales dijeron [los "señores del Cuzco] que eran bien lo ansi por él acordado que ellos estaban prestos e obedientes para hacer lo que ansi les mandase [el Ynga Yupangue]..." (Betanzos 1987:119 [1551: L I, cap. XXIII]).

Para el corpus de los ejemplos con respecto a las asambleas y al consenso emitido en ellas, me remito al Anexo de este trabajo, en donde están citados todos los casos de consenso que se refieren a prestaciones de trabajo y contribuciones estatales.

El relevamiento de esta modalidad consensuada en las asambleas Incas, que se repite en todo el texto y con los distintos Incas que se suceden a lo largo del tiempo, me lleva a postular que de hecho el Inca reinante debió negociar en primer lugar con los grupos sociales que los "Señores del Cuzco" representaron. (Estas negociaciones no se limitaron solo a los "Señores del Cuzco" sino que fueron llevadas paralelamente con las aristocracias provincianas, como explicaré más adelante).

Las negociaciones previas debieron representar conversaciones con cada uno de estos "Señores del Cuzco" por separado, con intercambio de regalos, chicha, coca y promesas de futuras recompensaciones para su grupo social y allegados, a cambio de la ayuda laboral para la empresa que el Inca plantearía en la asamblea.

Lo que sostengo es, que todo este proceso previo de negociaciones con la aristocracia cuzqueña y los mecanismos que lo hicieron posible no están relevados por la tradición oral en el texto. La explicación que encuentro a esta "omisión" es que para la experiencia de los informantes de Betanzos, el tener que negociar con otras familias y grupos sociales influyentes y poderosos, fue algo tan obvio y cotidiano que no se vieron en la necesidad de conservar y transmitir comportamientos diarios de tal naturaleza, y prefirieron hacer hincapié en los resultados de las conversaciones y tratativas, es decir en los acuerdos a los que pudieron llegar el fundador y los descendientes de su linaje real (Ynga Yupangue).

Además, esa misma tradición oral, es bien consistente con respecto a que el Inca fue la personificación del consenso, él lo construía, y su palabra una vez pronunciada en las asambleas fue la palabra final.

Ahora bien, si bien la tradición oral no consideró relevante apuntar dichas negociaciones específicas de cómo el Inca llegaba al consenso con los "Señores del Cuzco" y sus grupos de influencia, por otro lado, nos informa cómo debió proceder el buen gobernante Inca o el "señor" que tuviera cargos designados por la corte cuzqueña, en donde sí se reconocen esta modalidad del consenso, las negociaciones y el "consejo" por parte de los "Señores del Cuzco", en los procesos de toma de decisiones. 
Considerando que la siguiente cita viene a ser el "testamento político" que Ynga Yupangue legó a sus sucesores antes de morir, veamos qué principios y características para el buen gobierno le son atribuidos al fundador de dicho linaje real por los informantes de Betanzos.

[Ynga Yupangue] "dijo a los señores que alli presentes estaban y a sus hijos que después de sus días se supiesen conservar y que para su buena conservación que hiciesen y se gobernasen en la manera siguiente que en su pueblo y en los demás pueblos de toda la tierra que a sus gentes guardasen en justicia y que no consintiesen que entre los tales hubiesen discordia que si alguno se le rebelase o de los señores del Cuzco hiciesen alguna traición el cual fuese Ynga que lo matasen... que cuando pudiesen hacer bien a los suyos y darles de sus haciendas que siempre lo hiciesen y acostumbrasen que no consintiesen la ociosidad en su pueblo y en los demás pueblos y provincias... que cuando eligiesen Ynga o proveyesen algún cargo a algún señor del pueblo mirasen que el tal fuese hombre callado y no hablador y que cuando los tales señores estuviesen airados no proveyesen cosas sino con consejo que cuando estuviesen con gente de guerra sobre alguna provincia no se parasen con ellos a decirles cosas feas sino que antes procurasen hablarlos muy bien y amorosamente... que los señores del Cuzco con quien se debiesen de consejar fuesen los más ancianos y que dellos entendiesen que tenían mejores entendimientos y que más hubiesen andado en la guerra y allí dijo a Yamque Yupangue que siempre hiciese que Topa Ynga Yupangue anduviese conquistando y sujetando tierras y provincias que como anduviese en esta manera mientras fuese mancebo que vería más tierras y cosas de donde tuviese mejor entendimiento para cuando viniese a residir en su pueblo tuviese experiencia para regir y gobernar su pueblo y todo lo demás a él sujeto... que cuando batallar pudiesen con sus enemigos que antes que la diesen que mirasen primero como la debían de dar aunque muy poderosos de gente fuesen para ella... que si hubiese de dar cargo a alguno para regir y mandar en la república que mirasen primero de qué arte vivia en su casa y cómo vivía en ella y qué ordenaba en la demás hacienda y granjería della y que por allí verían si se le deberían de dar el tal cargo..." (Betanzos 1987:137/139 [1551: L I, cap. XXXX]).

El párrafo que cité es una parte de dicho "testamento". Ahora bien, cuáles son los elementos que lo caracterizan como parte de la tradición oral inca, y lo diferencian de un testamento europeo cristiano de los siglos XV-XVI.

Precisamente, creo que la clave para dilucidar esto se encuentra en la primera frase atribuida al Inca: "que en su pueblo y en los demás pueblos de toda la tierra que a sus gentes guardasen en justicia y que no consintiesen que entre los tales hubiesen discordia...". Si analizamos los conceptos de justicia y discordia, según los datos que nos brinda el Vocabulario de Diego González Holguín (1952 [1609]: 91; 490; 551) encontramos dos conceptos que confirman el origen inca de la tradición ya que apuntan a las 
nociones de "falta de conformidad", "prevención del mal" y "componer entre diferentes", es decir negociar.

La tradición oral recalca que el "buen Inca" no debía consentir las divisiones dentro de su propio pueblo, es decir prevenir desacuerdos y conflictos entre el grupo social inca, como así mismo en el resto del Estado. El papel primordial asignado por los informantes al "buen Inca", fue el de mediador de los conflictos y asegurador de la justicia. Pero además de estas funciones mediadoras y legitimadoras del Inca, los informantes hacen hincapié en el hecho de que el buen gobernante era el que consultaba y se apoyaba en el "consejo" de los otros. Como consta en la cita, el "consejo" al Inca era brindado por los "Señores del Cuzco" más ancianos, aquellos de "buen entendimiento". Esta cualidad se exigía a cualquiera que ejerciera un cargo en la burocracia estatal, aquellos con abundante y reconocida experiencia en los asuntos del gobierno y en las guerras (Betanzos 1987:115 [1551: L I, cap. XXII]).

Los viejos eran los encargados de ofrecer su información experimentada y estimada por tal. El Inca, recababa dicha información, escuchaba, opinaba, discutía. Su tarea era detectar los posibles factores de desacuerdo, prevenir la división, hablar con unos y otros, seguir escuchando la opinión de los viejos, de esta manera, crear el consenso que hiciera posible la toma de decisiones laborales y la planificación adecuada en las condiciones que se presentaban.

El consenso obtenido, no era un consenso general de toda la sociedad, sino era un equilibrio de consensos entre los viejos de la aristocracia cuzqueña que participaban en las asambleas y la propia opinión del Inca. Cuando se llegaba a tal equilibrio de opiniones, el Inca, como autoridad máxima pronunciaba "su palabra", la que a partir de ese momento, su pronunciamiento público, pasaba a ser la palabra del hijo del Sol, y por tanto inquebrantable, so pena de muerte. Recuérdese que lo que intento reconstruir en este análisis es el esquema de procedimientos ideológico-normativos del linaje de Ynga Yupangue y que en la práctica pudieron haber ocurrido "cambios" o variaciones (léase retractación de la palabra del Inca, nuevos compromisos, revalorización de la situación política, perdonar el castigo) ${ }^{2}$.

2 Con respecto a la reciprocidad negativa hay muy pocos ejemplos en la crónica de Betanzos, pero es de destacar que incluso en ellos el modelo que presento en este ensayo conserva las formas de la reciprocidad positiva. Véase Ziółkowski 1996: 334 para el análisis del error político de Guascar en la guerra contra Atahualpa, y del mismo autor pp. 236/239 para el conflicto de la rebelión de los Hurin- cuzcos y Guayna Capac. El problema de la reciprocidad negativa exige más ejemplos para su estudio, lo que dejo para otra oportunidad, $y$ me dedico a las abundantes muestras de reciprocidad positiva. 
También, como nos refieren los informantes, la autoridad Inca debía ser un "hombre callado y no hablador", es decir mesurado, equilibrado y que supiese guardar secretos (Betanzos 1987: 31[1551: L I, cap. VIII]; 1987:100 [1551: L I, cap. XX]; 1987:189 [1551: L I, cap. XIIV]).

Debía ser experimentado y haber pasado por distintos entrenamientos militares y de responsabilidades en el gobierno, proceso que comenzaban los jóvenes orejones cuzqueños (Betanzos 1987:119 [1551:L I, cap. XXIII]).

No solo debía tener edad y experiencia sino inteligencia, capacidad y habilidad en los asuntos públicos (Betanzos 1987:50 [1551:L I, cap. XI]; 1987: 132 [1551: L I, cap. XXVII]; 1987:175 [1551: L I, cap. XXXIX]).

Por último, la tradición oral nos informa que, el buen gobernante Inca debía comportarse como adulto y no como "mancebo". El mancebo era el joven que estaba en proceso de aprendizaje y adquisición de experiencias para el futuro.

Ahora bien, ¿El ser un "mancebo orejón" era simplemente ser un joven noble inca sin experiencia o además era el primer peldaño de responsabilidad y entrenamiento para el futuro dirigente inca?

Por los datos de los ejemplos que analicé me inclino a pensar que la segunda afirmación es la correcta. Los "mancebos orejones" eran justamente los mensajeros que se enviaban con las "órdenes del Inca" a los burócratas estatales y a los "caciques provinciales", debían saber guardar secretos y participar en las campañas militares (Betanzos 1987: 29 [1551:L I, cap. VII]; 1987: 100 [1551:L I, cap. XX]; 1987:120 [1551:L I, cap. XXIII]; 1987:175 [1551: L I, cap. XXXIX]).

Pero, además, a través de los años, estos "mancebos" aprendices de buenos gobernantes incas, debían adquirir el "buen entendimiento", es decir debían aprender a apoyarse en el "consejo" de los señores más ancianos. Debían aprender a escuchar opiniones y presiones diferentes, negociar las mismas y así llegar a obtener el consenso de los involucrados en la toma de decisiones y no decidir y gobernar sin el apoyo de los grupos de poder de la aristocracia cuzqueña (y a través de esta última, del apoyo de las aristocracias provincianas).

De allí, que en las dos citas que prosiguen, los informantes de Betanzos, pertenecientes al linaje de Ynga Yupangue y Atagualpa, acusen a Guascar, "hermano" y enemigo de éste último, de ser un mal gobernante, al tomar decisiones y posesiones sin el consenso y acuerdo de los interesados. Por tanto de comportarse de un modo que no corresponde al "buen Inca" y de manera reprochable: 
"Como fuese pasado el tiempo y días del ayuno en que Guascar estuvo para recibir la borla y el estado de Capac los señores del Cuzco que en aquella sazón estaban fueron al aposento do Guascar estaba y haciéndole su acatamiento como a tal señor pusiéronle la borla en la cabeza [este acto significaba la coronación del Inca]... el cual como se viese señor luego salió a la plaza y mandó que luego fuesen quitadas las tierras de coca y maíz al sol y a los demás bultos de los señores que eran muertos y las de su padre Guayna Capac todas las cuales aplicó para sí diciendo que el sol ni los muertos ni su padre que ya era muerto no comían y no comiendo que él las había menester lo cual fue muy aborrecible a los señores y pesábales viendo sus principios de le haber consentido que fuese señor el cual era muy vicioso en todos los vicios y más en la bebedez que muy pocos días había que no estuviese tomado y estando tomado de la embriaguez hacía mil desatinos como mancebo y muy liviano..." (Betanzos 1987: 207 [1551: L II, cap. I]).

"como viesen estas señoras [señoras aristócratas del Cuzco] que el Guascar era mancebo y que desde su niñez tenía más experiencia en beber que en cosas de guerra y que la gente que tenía era muy poca y supiesen la pujanza de los enemigos y sobre todo que el Guascar no era acogido a consejo ni parescer y que por su mesmo juicio se gobernaba no hicieron estas señoras yñacas caso de lo que el Guascar ni los demás señores les decían sino antes alcanzaban más su lloro e llanto..." (Betanzos 1987: 238 [1551: L I, cap. XII]).

Una fuente independiente con información de lo que significaba gobernar y obligación legal en la lengua quechua de principios del siglo XVII, es el ya citado Vocabulario de Diego González Holguín (1609). Allí observamos claramente que el mismo tema quechua KAMA + CHI (CAMACHI en el Vocabulario) significaba gobernar, ordenar por ley, ley y precepto, mandar, regir, pero al mismo tiempo acordar, consultar entre muchos, resolución de una consulta, consejo acertado. Los campos semánticos de dicho tema KAMA + CHI concuerdan con las informaciones que nos brinda la tradición oral conservada en la crónica de Betanzos, en donde las decisiones en el gobierno cuzqueño se tomaban acordadamente, con el consejo y consenso de los señores más ancianos participantes en las asambleas.

Cito los ejemplos de González Holguín:

"Acordar, o tomar acuerdo muchos consultar. CAMACHINACUNI.

Acordado consejo, o cuerdo. CAMACHINACUSCA.

Acuerdo de Oydores, o consulta, o cabildo. CAMACHINACUY.

Acuerdo o resolucion de la consulta. CAMACHINACUSCCA, o CAMACHINACUYPI RURAYPAC

ÑISCCA" (González Holguín 1952 [1609]: 385). 
"Consultar o hazer consulta. CAMACHINACUNI.

Consultores. CAMACHINANCUKCUNA.

Consulta. CAMACHINACUY." (González Holguín 1952 [1609]: 459).

"Gouernador juez. CAMACHICUK APU.

Gouernar el juez. CAMACHINI CAMACHICUNI TOKRINI TOKRICUNI.

Gouernar, 0 ordenar a otro, 0 endereçar su vida. CAMACHIPUNI MICHIPUNI CAUÇAYNINTAM CHECCAYACHINI YUYAPUCUNI." (González Holguín 1952 [1609]: 424).

"Obligar por ley. CAMACHICUNI CAMACHIYHUAN MANUCHAYCUNI.

Obligado a ley. CAMACHISCCA." (González Holguín 1952 [1609]: 604).

"Ordenar algo consultandolo. CAMACHINACUNI

Ordenar mandar poner ley. CAMACHINI.

Ordenación ley. CAMACHISCCA SIMI, o APUP CAMACHICUYNIN, o CAMACHISCCAN." (González Holguín 1952 [1609]: 609/610).

"Regir gouernar. CAMACHICUPUNI MICHICUPUNI CAUÇAYNINTAM CHECAYACHINI." (González Holguín 1952 [1609]: 657).

"CAMACHINI CAMACHICUNI. Ordenar, o consultar, lo que se ha de mandar CAMACHISCA CAMACHICISCA. Ley y precepto y mandamiento, 0 ordenança.

CAMACHIC CAMACHICLC. Gouernador, o corregidor, o mandon, o el que manda, o el que rige. CAMACHINACUNI. Consultar tratar en cabildo, o concertar, o ventilar algo muchos entre si. CAMACHIPAYANI. Mandar con demasia, o exceso sin orden." (González Holguín 1952 [1609]: 47).

Por otro lado, esta función mediadora y negociadora del Inca, como así también de las autoridades locales andinas (kurakas), ha sido subrayada e investigada por José Luis Martínez Cereceda en su libro "Autoridades en los Andes, los atributos del Señor" (1995:174).

Por último, investigaciones etnográficas en curso actualmente, realizadas por la antropóloga peruana Hilda Araujo en la comunidad de Tupicocha (sierra de Lima), confirman que las decisiones laborales, la organización de los trabajos en las distintas zonas de producción de los diferentes pisos ecológicos, y las dos asambleas generales anuales fijas, más las que se necesiten según las circunstancias, se realizan bajo el signo del consenso. Los campesinos no toman decisiones unilateralmente, sino hasta lograr el consenso de todos los participantes en las reuniones, "y si éste no se logra, se posponen las decisiones hasta la próxima vez, hasta que se llegue al consenso" (Comunicación personal: Abril 1998). 
Con esto no estoy afirmando que las asambleas de Tupicocha sean "descendientes o parientes" de las que realizaron en la corte cuzqueña de los siglos XV-XVI los "Señores del Cuzco", sino más bien resaltar el hecho de que en las condiciones ecológicas andinas, la solución de los problemas encuentra las mismas soluciones, es decir utiliza los mismos patrones culturales tradicionales: las negociaciones y el consenso.

\subsection{ETAPA DE EVALUACIÓN DE LAS FUERZAS LABORALES DISPONIBLES, REPARTO DE CONTRIBUCIONES Y REALIZACIÓN DE LA TAREA ESTATAL. (INCLUYE LOS MOMENTOS CLAVES DEL MODELO DESCRIPTTVO 9 AL 13).}

Una vez concluidas las negociaciones con los grupos de poder de la aristocracia cuzqueña, a través del consenso obtenido con los "Señores del Cuzco" que representaban a estos grupos, y por tanto de tomar las decisiones pertinentes para realizar una tarea estatal, se enviaban mensajeros (orejones "mancebos"), en demanda de las prestaciones de fuerza laborable a las provincias. Es importante recalcar que los mensajeros eran despachados por los "Señores del Cuzco" a cada sector del Tahuantinsuyu. (Más adelante en este mismo apartado analizaré por qué era función de estos "Señores", el envio de los mensajeros a los "caciques provincianos").

El pedido o "ruego" de prestaciones laborales a las provincias y a los cientos de grupos étnicos que conformaron el Estado Inca involucraba otra esfera de negociaciones, negociaciones directas con los grupos de poder locales de cada provincia.

No es esta la opinión de Demetrio Ramos, ya que en los Estudios Preliminares a la primera edición completa de la Crónica de Betanzos (1987) sostiene:

"No se nos habla por Betanzos de los indios del común, a los que según cabe deducir, se los deja por lógica en un plano de servidumbre ciega, tal como a los caciques se les sitúa, a pesar de esas juntas a las que se les ve acudir al Cuzco, llamados por el Inca, para prestar acatamiento a cuanto se dispone por él. Mas todo, se conforma con aquella impresión de Karsten, quien caracterizó al Incario como un Estado Totalitario..." (Ramos 1987: LXXV).

Sin embargo, volviendo al texto del cronista, lo que rescato de la tradición oral allí conservada, es precisamente el acuerdo concertado y las negociaciones con los "caciques provincianos".

El pedido o "ruego" de prestaciones laborales a los "caciques provincianos", además de ser ceremonialmente realizado y dentro de las tradicionales pautas de reciprocidad y redistribución andinas, era un pedido según las posibilidades demográfi- 
cas, ecológicas, de capacitaciones técnico-laborales, sociales y políticas de los grupos étnicos y no una orden sin más del Inca, en donde se estipulaba la cuota e incluso la fecha de entrega de dichas prestaciones laborales. La fecha de las prestaciones de ayuda se podía negociar, el reparto de las contribuciones se acordaba en cada tarea, e incluso los caciques se podían negar a brindar dicha ayuda.

Las autoridades cuzqueñas negociaban en cada oportunidad las relaciones laborales con los poderes locales en juego. Así, ambas partes: Estado y provincias defendían y propiciaban sus diferentes intereses.

Citaré ejemplos de lo sostenido en este párrafo.

"e los tales señores e caciques se fueron de alli derecho do Viracocha Ynga estaba e después de le haber hecho su debido acatamiento... le dijeron como Ynga Yupangue los enviaba allí a que viese en qué era servido que ellos le sirviesen e como Viracocha Ynga los viese delante de sí y tan gran multitud de señores y de tanto poder holgóse mucho dello porque dellos tenía gran necesidad al presente para que le favoresciesen con algún tanto de su gente para edificar aquel pueblo que allí quería hacer y dijoles que fuesen muy bien venidos e levantóse de su asiento y abrazolos a todos e tornose a sentar y mandólos a todos que ansi se asentasen e mandó que sacasen mucha chicha e que les diesen a beber e luego les hizo sacar mucha cantidad de coca...e Viracocha Ynga les rogó que por cuanto él quería allí en el peñol donde estaba edificar un pueblo que para ello tenía necesidad de su ayuda e gente e que les rogaba que tuviesen por bien de darle aquel ayuda a lo cual le respondieron aquellos señores que ellos habían venido allí para que él viese en lo que ellos le pudiesen hacer algún servicio..." (Betanzos 1987: 46/47 [1551: L 1, cap. X]; 1987: 61 [1551: L I, cap. XIII]).

El pedido de ayuda laboral para construir un pueblo nuevo, como consta en la cita precedente fue realizado dentro de un marco ritualizado, en donde cada parte desempeñó su papel de acuerdo a las pautas de reciprocidad vigentes en los Andes. El Inca recibió a los "Señores del Cuzco" y a los "caciques provincianos", y les rogó su ayuda, asimismo los obsequió con abundante chicha y coca, dos elementos rituales imprescindibles y prestigiosos en toda reunión. El comportarse de esa manera, era honrar la presencia de los invitados y reforzar las relaciones político laborales de los involucrados. Por otro lado los "caciques" y "señores" hicieron el debido acatamiento y aceptaron dicha relación laboral al pronunciarse en favor de la tarea.

Ahora bien, los informantes de Betanzos nos relatan un caso en donde los "caciques provincianos" negaron dicha ayuda laboral al Inca, no por que el Inca no cumplió con sus "obligaciones rituales de pedido", sino que dependió de la situación política 
particular en que fue realizado el pedido de la prestación laboral. La situación política particular a que me refiero fue una guerra (la guerra contra los Changas), es decir fue un momento de crisis para el gobierno inca. Citaré el ejemplo en cuestión:

[Los "caciques provincianos" le responden a Ynga Yupangue a su pedido de mano de obra guerrera para luchar contra los enemigos changas] "nos paresce que el poder de Uscovilca Changa que sobre él e sobre nos tiene que es mucho y muy grande y que como él no tenga más gente de a su persona y a sus compañeros y que el poder que ellos le podían dar y ayuda era ansi mesmo poco y que no le podían socorrer... más que lo que ellos harian era que como él buscase de alguna parte o por alguna via tuviese algún tanto de poder de gente que ellos ansi mismo estaban prestos de le ayudar..." (Betanzos 1987: 29 [1551: L I, cap. VII]).

Como vemos en la cita, los "caciques provincianos" evaluaron bien el tipo de alianza que le convenía y las fuerzas disponibles de cada uno en la guerra, y prometieron su posible ayuda de guerreros a condiciones previas que el Inca debía cumplir. Si bien, se negaron a la prestación laboral, seguramente por el estado de crisis del gobierno inca, no rompieron los lazos para futuros acuerdos.

El hecho de que se negociaban las prestaciones laborales entre el poder central y las provincias está permanentemente referido por la tradición oral que analizo. Otro ejemplo de dichas negociaciones es la cita que prosigue:

„mandó que todos los señores de la ciudad del Cuzco y los demás caciques y principales se juntasen en la plaza los cuales ansi fueron juntos e siendo allí todos dijoles que él tenía noticia que en torno de la ciudad del Cuzco habia mucha y muy gran cantidad de pueblos e provincias y para él que tenía fuerzas que era mal vivir con poco que tenía pensado y ordenado de se partir de aquella ciudad de allí en dos meses a buscar adquirir e sujetar los tales pueblos e provincias... a lo cual le respondieron que ellos estaban prestos de le dar la tal gente y servir con ella y que ansi irian con sus personas que le rogaban que consigo los quisiese llevar e que fuese su voluntad de les dar espacio de tres meses porque tenían necesidad del tal tiempo para hacer la tal junta e Pachacuti Ynga Yupangue holgóse dello mandándoles que en sus tierras dejasen todo recaudo de principales e mayordomos los cuales tuviesen cuidado de hacer sembrar muchas e muy grandes sementeras porque entendía que les sería menester según el tiempo que él tenía pensado de andar en la guerra e luego les mandó que ansi se partiesen e que como llegasen a sus tierras e provincias diesen la orden en hacer la tal junta para que viniese alli en fin de los tres meses..." (Betanzos 1987: 87 [1551: L I, cap. XVIII]).

Si bien, la "planificación del Inca" fue reunir una fuerza guerrera para la campaña militar en dos meses, los caciques consideraron escaso el tiempo y "pidieron", negociaron, otro mes. Finalmente se llegó al acuerdo de tres meses para reunir la gente 
necesaria, vale decir, se tuvieron en cuenta las necesidades del calendario local, y de alguna manera se lo coordinó con lo programado por las autoridades centrales.

A continuación citaré otras variables que se tuvieron en cuenta para negociar con los poderes locales, además del período de tiempo.

[Ynga Yupangue negocia las contribuciones laborales con caciques recientemente incorporados al Tahuantinsuyu, luego de la derrota de los señores Soras] "los caciques le respondieron que ellos lo harían como se los mandaba pues eran sus vasallos pues les repartiese y mandase a cada uno dellos e señalase qué había de tributar y qué tanto y el Ynga les mandó que le dijesen qué tenían en sus tierras y qué posibilidad alcanzaba cada uno y que le dijesen la verdad porque él tenía ordenado de poner en cada provincia de cada uno de ellos un orejon señor natural del Cuzco a quien ellos y cada uno de ellos respetase en su tierra como a su persona el cual sabría lo que ansi cada uno tenía e poseía e como él supiese que le había dicho mentira cualquiera dellos que entendiese que había de morir por ello... dio y señaló a cada uno dellos memoria de lo que ansi había de traer e tributar a él y a la ciudad del Cuzco y a unos mandó que tributasen maíz y a otros ovejas y otros ropa y otros oro y otros plata e ansi de las demás cosas dando e señalando a cada uno tributos moderados tales que sin dejación e molestia alguna los pudiesen dar..." (Betanzos 1987: 96/97 [1551: L I, cap. XIX]).

Vemos, en la cita, que los pedidos de contribuciones laborales por parte de las autoridades cuzqueñas a los "caciques provincianos", se re-negociaron con cada uno, no se estipularon cuotas fijas de prestaciones para todos igual, sino más bien estas contribuciones fueron resultado de las negociaciones con esos mismos poderes locales y habiendo tenido en cuenta las condiciones ecológicas y demográficas de los grupos contribuyentes. (Otros ejemplos en Betanzos 1987: 75 [1551: L I, cap. XV]]; 1987:100 [1551: L I, cap. XX]; 1987:127 [1551:L I, cap. XXVI]; 1987:155 [1551: L I, cap. XXXIV]; 1987:187 [1551: L I, cap. XIIII]).

Además el Estado contaba con un aparato burocrático que controlaba el curso y cumplimiento de los acuerdos, como fue el caso de los gobernadores provinciales, descriptos en la cita, más todo el resto de los componentes del circuito informativo, al que ya me referí anteriormente.

De esta manera, así como se establecían las negociaciones para las contribuciones laborales, el "cacique provinciano" que rompiera dichas negociaciones unilateralmente (rebeldes o mentirosos), era considerado un criminal merecedor de la muerte, como también lo aclara la cita precedente (Betanzos 1987:113/117 [1551: L I, cap. XXII]; Ziółkowski 1996: 242). 
Ahora bien, una vez pedida, negociada y obtenida la ayuda laboral de los grupos de las provincias por parte del poder central del Cuzco, los "caciques" llegaban a la capital con su gente en la fecha prevista y estipulada de antemano. Se presentaban ante el Inca y los "Señores del Cuzco" que los recibían y agasajaban con fiestas, coca y abundante chicha. Luego, los "caciques" realizaban la ceremonia del "acatamiento" con la consiguiente entrega de regalos y sacrificios al Inca.

Acto seguido, el Inca anunciaba públicamente ante todos los "caciques" la tarea por la que se los había llamado y éstos expresaban su consentimiento y buena voluntad de realizarla. Este anuncio del Inca, así como el consentimiento de los "caciques", era un acto formal en donde se expresaban públicamente los consensos y acuerdos que ya se habían negociado separadamente con cada uno de ellos, unos meses antes de la tarea, con el envío de los mensajeros cuzqueños a las provincias. La cita a continuación releva este aspecto de las relaciones laborales:

„e llegados que fueron [los "caciques"] a la ciudad del Cuzco hicieron su acatamiento al Ynga... ponianle delante sus presentes que ansi le traían e luego le sacrificaban ciertas ovejas e corderos delante del con todo el respeto e acatamiento como a hijo del sol y esto ansi hecho el Ynga los saludaba diciendo que fuesen bienvenidos e preguntándoles si venían buenos e si lo estaban ansi mismo en sus tierras... y después de se haber holgado con el Ynga e con los señores del Cuzco cinco días en sus fiestas e regocijos Ynga Yupangue les dijo lo que pensaba hacer e como quería reparar e fortalecer aquellas veras de aquellos dos arroyos que por la ciudad pasaban contándoles el periuicio que la ciudad de los tales arroyos recibía y ellos dijeron que estaban prestos para hacer todo aquello que por él les fuese mandado..." (Betanzos 1987: 59/60 [1551: L I, cap. XIII]).

De hecho los encargados directos de organizar las relaciones laborales y llevar a cabo las negociaciones y acuerdos de las contribuciones estatales con los "caciques provincianos", fueron los "Señores del Cuzco", mientras que el Inca fue ideológicamente el garantizador político y divino de dichas relaciones laborales y políticas.

La tradición oral es muy abundante en ejemplos que señalan el tipo de funciones que realizaron estos "Señores del Cuzco", de allí la importancia de sus opiniones, presiones y consensos. De allí también la tarea constante del Inca reinante de buscar el apoyo político y económico de estos "Señores del Cuzco".

Los informantes de Betanzos si bien fueron "reservados" en cuanto a la identidad de los "Señores del Cuzco" y los grupos que ellos representaron, afortunadamente, no 
lo fueron con respecto a las funciones preponderantes que cumplieron en la administración y política del Estado Inca.

Sencillamente fueron estos "Señores del Cuzco" a través de abundantes e intrincados lazos políticos y de parentesco los que "dirigieron" las negociaciones con las aristocracias provincianas en lo que respecta a la producción de excedentes alimentarios y así mismo, fueron los que dirigieron los ejércitos del Inca.

Pero entiéndase bien, así como el Inca no decidía sin "su consejo", estos "señores orejones del Cuzco" tampoco podían decidir la organización laboral, el reparto de las tareas y las contribuciones estatales sin los acuerdos y pactos con los "caciques provincianos".

La tradición oral menciona siempre, como paso previo a la realización de la tarea 0 salida a la campaña militar, el recuento de la ayuda laboral prestada. Esto, como apunté anteriormente, era de capital importancia como información para la planificación de las cargas y obligaciones de cada grupo de gente. El recuento lo realizaban los "Señores del Cuzco" junto con los "caciques provincianos". Los "caciques" eran los encargados y responsables directos de sus propios "indios", vale decir que el control que tuvo el poder central cuzqueño sobre la fuerza laborable, fue indirecto. (Hay que remarcar que se trató de los "indios" que estaban bajo la administración de las autoridades locales tradicionales y en sus propias provincias, y no de otras categorías laborales de gente que fueron extraídas de sus grupos étnicos y que sí fueron directamente administrados por el poder central).

En la cita que presento a continuación, los informantes de Betanzos revelan este control indirecto de la fuerza laborable:

„Ynga Yupangue mandó a los tres sus buenos amigos ["Señores del Cuzco"] y a los demás caciques y señores que en socorro e servicio habían venido que luego juntasen la gente de guerra y que la sacasen a cierto campo cada uno con sus armas e que los contasen uno a uno e siendo sacados e contados halláronse de número de cien mil hombres de guerra ...y ansi mandó Ynga Yupangue que fuesen hechos cuatro escuadrones destas su gente mandando que cada cacique señor de los indios que allí eran fuese caudillo de su gente y ansi repartió por generales de los tres escuadrones a sus tres buenos amigos tomando para sí el uno de ellos y proveídos todos ellos de las armas necesarias mandó marchar su campo en busca de sus enemigos ..." (Betanzos 1987:44 [1551: L I, cap. X]).

Aquí vemos diversos niveles de administración laboral coordinada: el Inca en persona fue el comandante general del ejército estatal, los "Señores del Cuzco", fueron los 
generales y los "caciques provincianos "fueron los que dirigieron directamente a su gente (en la cita no se mencionan jerarquías aún menores, que seguramente las hubo).

Insistiré con otro ejemplo, en donde se visualiza bien esta coordinación y superposición de la administración laboral:

„mandó el Ynga que luego saliesen de la ciudad del Cuzco cierta suma de orejones los cuales fuesen por las tierras de aquellos señores que allí eran ["caciques provincianos" invitados en la ciudad del Cuzcol e supiesen e le trajesen por cuenta qué suma había en las tales tierras e pueblos de mancebos solteros e mozas solteras mandando a los caciques e principales que enviasen a hacer saber a sus mayordomos llactacamayos que ellos llaman que aquella era su voluntad e mandó que luego con toda brevedad les diesen la cuenta a los tales orejones de lo que ansi enviaba a saber...e habido por los orejones en los tales pueblos e provincias la cuenta e razón de su demanda volvieron a la ciudad del Cuzco...y entendido por el Ynga la cantidad de mancebos e mozas solteras que habia en los tales pueblos e provincias mandó a aquellos señores sus tres buenos amigos que luego se partiesen para los tales pueblos e provincias e que llevasen consigo todos los caciques e señores que al presente allí eran con él en presencia de los cuales en cada pueblo e provincia que llegasen casasen los mancebos de una provincia con las mozas solteras de la otra e ansi fuesen haciendo por las tierras e subjeto de quellos señores caciques que con él eran para que creciesen e multiplicasen e tuviesen perpetua amistad deudo y hermandad los unos con los otros y esto ansi proveído el Ynga hizo muchas grandes mercedes a aquellos señores caciques dándoles muchas dádivas..." (Betanzos 1987: 62 [1551: L I, cap. XIII]).

En el precedente ejemplo la tradición oral nos refiere otras instancias organizacionales de la fuerza de trabajo (recuérdese que solo realizaban prestaciones laborales al Estado, las personas casadas). En dicha cita encontramos la actuación coordinada de los siguientes niveles de administración laboral: los "Señores del Cuzco" ("aquellos señores sus tres buenos amigos"), los orejones enviados a las provincias, los "caciques y principales provincianos" y un organizador laboral local ("mayordomo"), que se encontraba en la aldea y manejaba directamente los cómputos de los perfiles demográficos de la población local.

La información demográfica obtenida en las aldeas provincianas, volvía luego al Cuzco, seguramente en forma de khipu, aunque no sabemos si hubo algún otro medio de transmisión. De alguna manera debieron de estandarizar dicha información para que les fuera útil y práctica en la planificación de las tareas, tampoco esto sabemos cómo lo resolvieron. Lo que sí es claro en la crónica de Betanzos, es que la guarda y manejo de los khipu, con información clave de todo tipo, fue una tarea conjunta de los dos poderes en juego, el central representado por los "Señores del Cuzco", y el local, 
por los "caciques provincianos". En la cita precedente se nos habla del procesamiento de la información demográfica y en la siguiente, del procesamiento de la información ecológica y de los recursos económicos de las provincias:

"el Ynga les mandó que le dijesen qué tenían en sus tierras y qué posibilidad alcanzaba cada uno... luego los caciques mandaron traer alli los quipos memorias que ellos tienen y ansi mesmo por pinturas lo que ansi tenían e poseían y del arte y suerte que era la tierra e provincia de cada uno dellos y uno dijeron tener ganados otros grandes tierras de maiz e otros minas de oro y otros minas de plata e otros mucha madera y ansi de las demás cosas e menesteres todo...lo cual visto por el Ynga mandó llevar los señores principales de la ciudad que ansi él tenía señalado que tuviesen cuenta y razón con los tales señores e caciques de lo que ansi traían y tributaban e siendo allí mandó traer muchos cordeles de lana de diversos colores e tomando cada cacique por sí delante de aquellos señores del Cuzco e haciendo nudos en aquellos cordeles dio y señaló a cada uno dellos memoria de lo que ansi había de traer e tributar a él y a la ciudad del Cuzco... señalando a cada uno tributos moderados tales que sin dejación e molestia alguna los pudiesen dar mandando hacer destos quipos e memorias dos uno que llevase el tal cacique e otro que quedase en poder de aquellos señores..." (Betanzos 1987: 96/7 [1551: L I, cap. XIX]).

Para otros ejemplos de contabilizar la ayuda laboral, control indirecto de la mano de obra y procesamiento de la información véase: (Betanzos 1987: 87 [1551: L I, cap. XVIII]; 1987: 100 [1551: L I, cap. XX]; 1987: 156 [1551: L I, cap. XXXIV]; 1987: 173 [1551: L I, cap. XXXVIII]; 1987: 187 [1551: L I, cap. XIIII]; 1987: 238 [1551: L II, cap. XII]; 1987: 289 [1551: L II, cap. XXVIII]).

El reparto de las prestaciones y contribuciones laborales para las tareas estatales fue también función conjunta de los mismos personajes recordados por la tradición oral: los "Señores del Cuzco" y los "caciques provincianos". (Betanzos 1987: 47 [1551: L I, cap. X]) 1987: 56/57 [1551: L I, cap. XII]; 1987: 60 [1551: L I, cap. XIII]; 1987: 173 [1551: L I, cap. XXXVIII]; 1987: 289 [1551: L II, cap. XXVIII]).

Así mismo, los "Señores del Cuzco" y los "caciques provincianos", compartieron la función de almacenar las contribuciones de excedentes alimenticios, de ropas y demás "mantenimientos" que entregaban las provincias, en los depósitos estatales del Cuzco (Betanzos 1987: 62 [1551: LI, cap. XIII]), y por consiguiente llevar sus cuentas, como consta en la cita a continuación:

[Ynga Yupangue dice a los "caciques provincianos" que entregan sus tributos en el Cuzco] "díjoles que diesen aquello que ansi tráan a aquellos señores del Cuzco que allí estaban e ansi se salieron de donde el Ynga estaba y ellos y aquellos señores del Cuzco fueron donde los depósitos 
eran y pusieron todo el mantenimiento que traían a recaudo..." (Betanzos 1987: 60 [1551: L I, cap. XIII]).

Ahora bien, si resumo todas las funciones con respecto a las relaciones laborales que la tradición oral conservada en Betanzos asignó a los "Señores del Cuzco", obtengo el siguiente listado:

- Enviar mensajeros orejones a las autoridades provinciales. (Betanzos 1987: 55 [1551: L I, cap. XII]; 1987: 100 [1551: L I, cap. XX]; 1987: 169 [1551: L I, cap. XXXVII]; 1987: 173 [1551: LI, cap. XXXVIII]; 1987: 274 [1551: L II, cap. XXII]).

— Organizar la mano de obra junto con los "caciques". (Betanzos 1987: 56 [1551: L I, cap. XII]; 1987: 57 [1551: L I, cap. XII]; 1987:75 [1551: L I, cap. XVI]; 1987: 170 [1551: L I, cap. XXXVII]; 1987: 173 [1551: L II, cap. XXXVIII]; 1987: 187 [1551: L I, cap. XIIII]; 1987:215 [1551: L II, cap. V]; 1987: 289 [1551: L II, cap. XXVIII]).

- Encargarse de los excedentes que entran y salen de los depósitos del Cuzco. (Betanzos 1987: 60 [1551: L I, cap. XIII]; 1987: 62 [1551: L I, cap. XIII]).

- Encargarse de contabilizar y guardar los cómputos de las contribuciones laborales de las provincias (responsables de los khipu junto con los “caciques"). (Betanzos 1987: 44 [1551: L I, cap. X]; 1987: 62 [1551: L I, cap. XIII]; 1987: 96/7 [1551: L I, cap. XIX]; 1987: 100 [1551: L I, cap. XX]; 1987: 156 [1551: L I, cap. XXXIV]; 1987: 173 [1551: L I, cap. XXXVIII]; 1987: 187 [1551: LI, cap. XLIII]; 1987: 238 [1551: L II, cap. XII]).

- Administrar de manera total y general los ganados estatales y del sol. (Betanzos 1987:105 [1551: L I, cap. XXI]; 1987:176 [1551: L I, cap. XXXIX]).

- Visitar las cuatro provincias del Tahuantinsuyu. (Betanzos 1987:179 [1551: L I, cap. XI] ; 1987:181 [1551: L I, cap. XLI]; 1987: 197 [1551: L I, cap. XIVII]).

- Controlar las obras estatales junto con el Inca. (Betanzos 1987: 50 [1551: L I, cap. XI]; 1987: 173 [1551: L I, cap. XXXVIII]; 1987: 215 [1551: L II, cap. v]).

— Encargarse de asuntos religiosos y rituales. (Betanzos 1987:62 [1551: L I, cap. XIII]; 1987: 84 [1551: LI, cap. XVII]; 1987: 88 [1551: LII, cap. XVIII]). 
— Dirigir como generales los ejércitos del Inca. (Betanzos 1987: 44 [1551:L I, cap. X]; 1987: 90 [1551: L I, cap. XVIII]; 1987: 120 [1551: L I, cap. XXIII]).

-Elegir al futuro Inca. (Betanzos 1987: 31 [1551: L I, cap. VIII]; 1987: 81 [1551: L I, cap. XVII]; 1987: 194 [1551: L I, cap. XIVI]).

Una vez considerado este listado de funciones de los "Señores del Cuzco", y teniendo en cuenta dos fenómenos, a saber: que el número de los grupos étnicos que conformaron el Estado Inca fue grande, y debió ser considerablemente mucho mayor, a medida que se expandió rápidamente en territorio andino, (Betanzos 1987: 23 [1551: L I, cap. VI]), y así mismo considerando el tipo de coordinación y planificación que caracterizaron la organización laboral Inca, sostengo los siguientes postulados:

-En las asambleas del gobierno Inca hubo una división espacial de funciones de los "Señores del Cuzco" y de los "caciques provincianos" relacionada con las prestaciones laborales.

-Esta división espacial de funciones fue por lo menos una división en cuatro sectores o "suyu" (Chinchaysuyu, Andesuyu, Collasuyu y Cuntisuyu) para la organización de la ciudad del Cuzco (y seguramente de manera simbólica para el resto del Estado).

-Esta división espacial en cuatro sectores de organización laboral en la ciudad del Cuzco, incluyó también a los grupos étnicos representados por los "caciques provincianos" respectivos.

-Evidentemente las aristocracias provinciales influyeron en las decisiones laborales tomadas en el Cuzco, justamente a través de sus relaciones y negociaciones directas con los "Señores del Cuzco".

De allí que, los encargados de enviar mensajeros ("orejones mancebos") a los "caciques provincianos" y a las autoridades estatales residentes en las provincias, fueran los "Señores del Cuzco" según esa misma división espacial, lo mismo que los encargados de almacenar en los depósitos lo entregado por los "caciques", o de visitar e inspeccionar el territorio de su competencia. (Véase las citas respectivas en el listado de funciones de los "Señores del Cuzco" más arriba).

Así llegamos, a lo que creo fundamental entender de la organización laboral en los Andes en general y en particular de la organización laboral de lo que fue el Estado Inca de los siglos XV-XVI: sin información precisa, organización del trabajo, planificación conjunta, sin un calendario agrícola común que considerase tanto las necesidades del 
poder central como las necesidades de las etnias provincianas, sin acuerdos para la utilización de determinadas tecnologías agropecuarias, sin esta división espacial mínima de funciones entre los cuatro sectores laborales para la ciudad del Cuzco (aunque pudo haber otras divisiones menores dentro de estas mayores que la tradición oral no revela), en resumen, sin un consenso mínimo, no se pudo haber llegado al nivel tecnológico y de reservas alimentarias al que se llegó en el Estado Inca de los siglos XV-XVI (y en esto último concuerdan todos los cronistas).

En un ecoambiente tan complejo y cambiante como el andino, solo una administración laboral coordinada y negociada, entre los diversos niveles de planificación laboral, pudo hacer posible el grado de control y organización del espacio y de la energía humana que nos consta en la tradición oral conservada en Betanzos (Sternfeld 1998: 1/7).

\subsection{ETAPA DE FINALIZACIÓN DE LA TAREA ESTATAL CON LAS CONSIGUIENTES FIES- TAS, SACRIFICIOS, CEREMONIAS RITUALES Y REPARTO DE REGALOS Y MERCEDES. (INCLUYE LOS MOMENTOS CLAVES DEL MODELO DESCRIPTIVO 14 Y 15).}

Una vez finalizada la tarea estatal, el gobierno central, a través de la jerarquía social máxima y divina encarnada por el Inca, "devolvía", es decir redistribuía asimétricamente, a los grupos étnicos y grupos de poder en general, que aportaron la ayuda laboral, con tareas de administración y burocracia, con intermediación en los cultos religiosos y con ayuda alimentaria en caso de desequilibrio ecológico.

La tradición oral conservada en la crónica de Betanzos es bien profusa en ejemplos de esta redistribución asimétrica, así, los "caciques provincianos" recibían bienes suntuosos con un alto grado de prestigio social y ritual, tales como tejidos finos y vestidos del propio Inca, ganado en pie, joyas de oro y plata, hojas de coca y chicha, esposas de los linajes reales, permiso especial de llevar algún tipo de atavío que expresara jerarquía social. (Betanzos 1987: $57 / 58$ [1551: L I, cap. XII]; 1987: 137 [1551: L I, cap. XXIX]; 1987: 167 [1551: L I, cap. XXXVI]; 1987: 175 [1551: L I, cap. XXXIX]; 1987: 179 [1551: L I, cap. XI] ; 1987: 46 [1551: L I, cap. X]; 1987; 44 [1551: L I, cap. X]).

A su vez el Inca y la aristocracia inca, tomaban como esposas secundarias para sí, a las mujeres parientes de estos mismos "caciques provincianos", o a sus hijos 0 hermanos como servidores en la corte cuzqueña. Creándose así una intrincada y extensa red de parentesco, lo cual recreaba lazos y alianzas y llevaba a complicadas 
negociaciones políticas que servían a la redistribución asimétrica estatal. (Murra 1975:145-170; Pease 1991: 54; Pärssinen 1992:152-160).

Esta política de alianzas matrimoniales fue absolutamente consciente y fue practicada sistemáticamente por parte del Estado Inca, intentando revestir ideológicamente las relaciones laborales asimétricas con las provincias, con unas relaciones de parentesco que obligaban socialmente a quienes las contraían. La cita a continuación es un ejemplo de esta política.

[Ynga Yupangue] "hizo traer todas sus hijas allí delante de sí lodas las cuales eran doncellas y como allí fuesen diolas a los señores principales de la ciudad del Cuzco que allí estaban por mujeres y algunas dellas mandó que fuesen casadas con ciertos señores caciques principales de la tierra con el cual beneficio los trujo a más amor a su hijo Topa Ynga Yupangue y esto hecho repartió todos sus bienes como mejor le paresció..." (Betanzos 1987: 137 [1551: L I, cap. XXIX]).

Pero lo interesante de todo ello, es que dicha redistribución asimétrica estatal, según los informantes de Betanzos, se realizaba también dentro del ámbito de las asambleas. Se trataba de un acto público, con una carga simbólica muy fuerte, ya que era en presencia del Inca o de sus enviados especiales para tal efecto, como era el caso de los "Señores del Cuzco" y en presencia de todos los "caciques" merecedores de tales "mercedes" por prestarse a las contribuciones laborales "rogadas" por el Estado.

En este tipo de asambleas se creaban y/o reafirmaban alianzas con los "Señores del Cuzco", sus parientes y allegados y con los "caciques provincianos", que devenían luego en futuras negociaciones y pactos de prestaciones laborales. Cumpliéndose, de esta manera, con la regla general andina, a saber: el que "da" tiene derecho luego a "pedir". En el ejemplo que presento a continuación vemos cómo los informantes hacen hincapié en que fue justo "devolver" por parte del poder central, la ayuda de las prestaciones laborales, pero a su vez, fue conveniente y necesario para mantener las buenas relaciones con las provincias:

\footnotetext{
"acabadas todas de reparar [las veras de los dos arroyos del Cuzco] Ynga Yupangue mandó juntar los caciques e señores que en todo lo ya dicho le habían hecho servicio e paresciéndole que era justo hacerles algunas mercedes e darles algún contentamiento e siendo ansi juntos dióles e repartióles muchas joyas de oro y plata que mediante aquel tiempo que en la obra estivieron [sic] él había mandado labrar e ansi mismo les dió cada dos vestidos de las ropas de su vestir e a cada uno dellos les dió unas señoras naturales del Cuzco y de su linaje para que fuesen cada una destas mujer principal del cacique a quien ansi le habian dado
} 
e que los hijos que en las tales hubiesen fuesen herederos de los tales estados e señorios que sus padres tuviesen fundándose Ynga Yupangue que por el deudo que con ellos por esta vía había que nunca ninguno dellos en sus dias se le rebelaría e que habría entre ellos e los de ciudad del Cuzco perpetua amistad y confederación todo lo cual ansi hecho y visto por los caciques las grandes mercedes que les hacía todos se inclinaron a le besar los pies y le dar grandes gracias a los cuales mandó Inga Yupangue que se fuesen a descansar a sus tierras y que dentro de un año volviesen a la ciudad del Cuzco e que mediante este tiempo cada uno dellos en sus tierras hiciesen sembrar muchas sementeras de todas comidas porque tenía que serían menester andando el tiempo e que les encomendaba que en sus tierras no hubiese ociosidad en los mancebos ni en las mujeres... todo lo cual oído por los caciques dijeron que ansi lo harían e que él les decía lo que era bueno y ansi el Ynga los despidió y ellos haciendo su acatamiento se salieron y se fueron para sus tierras." (Betanzos 1987: 57/ 58 [1551: L I, cap. XII]).

La entrega de "dádivas y mercedes" prestigiosas a las aristocracias tanto cuzqueñas como provincianas intentaba así, asegurar cierta "pax Inca" (Betanzos 1987: 167 [1551: L I, cap. XXXVI]; 1987: 175 [1551: L I, cap. XXXIX]).

De hecho, no siempre se logró mantener dicha "pax", sobre todo en los momentos inmediatamente siguientes a la muerte del Inca reinante y la elección del sucesor, en donde como nos relatan los informantes en la crónica, hubo rebeliones y crisis políticas en la corte cuzqueña. (Betanzos 1987: 151 [1551: L I, cap. XXXIII]; 1987: 153 [1551: L I, cap. XXXIII]; 1987: 177 [1551: L I, cap. XXXIX]; 1987: 182/183 [1551: L I, cap. XII]; Ziółkowski 1996: 184). Otra causa posible para las rebeliones, aunque no mencionada en la crónica, pudo haber sido el fenómeno de las hambrunas que sufriera la población, producto de crisis ecológicas.

Para más ejemplos de este tipo de asambleas de establecimiento y/o afianzamiento de relaciones políticas y laborales véase el Anexo de este trabajo.

Un aspecto que vale la pena mencionar, aunque no es mi intención desarrollar en este ensayo, es el aspecto religioso- ritual de todos estos procesos decisivos con respecto al trabajo. El hecho de que la tradición oral mencione al Inca como hijo del sol, a los "Señores del Cuzco" y al mismo Inca sentados en "tiyanas", como hemos analizado en su condición de wakas o seres sagrados, el peregrinaje de informaciones y de personas (mensajeros, "caciques", trabajadores/soldados) hacia el Cuzco y desde el Cuzco como centro imprescindible, nos dan ciertas pautas para pensar en la fuente religiosa de la autoridad inca. Vale decir, lo religioso y lo ritual fueron aspectos constitutivos de los procesos decisivos y ejecutivos laborales en la corte cuzqueña de los siglos XV-XVI. 
Para finalizar quiero citar a Franklin Pease, cuyas apreciaciones corroboran lo expuesto en este apartado de mi trabajo.

"Así, la interdependencia de los curacas con el Inca, (ergo, con la de los grupos étnicos del Cuzco) se hallaba garantizada por una serie de convenios de redistribución negociada, que incluían la entrega de energía humana al poder central y la recepción de determinados bienes de la redistribución. Como se ha enfatizado demasiado la imagen de la expansión militar del Tahuantinsuyu - debido a que los cronistas hispánicos sólo entendían así la expansión - se ha dejado mucho tiempo de lado las propias sugerencias de las crónicas acerca de estos convenios. (...) La redistribución en sí no excluye el conflicto, por cierto, pero admite diversas formas de consenso que la investigación debe abundar" (Pease 1992: 30/31).

\section{LAS ASAMBLEAS}

En el apartado anterior de este ensayo, analicé los acuerdos y negociaciones que el Estado Inca llevó a cabo con los diferentes grupos de poder que lo conformaron e influyeron, con respecto a las prestaciones laborales y a las relaciones políticolaborales, según la tradición oral conservada en la crónica de Betanzos.

Dicho análisis lo encaré en las tres etapas del modelo descriptivo de toma de decisiones laborales que elaboré:

- Etapa de toma de decisiones y planeamientos para la realización de una tarea estatal.

-Etapa de evaluación de las fuerzas laborales disponibles, reparto de contribuciones y realización de la tarea estatal.

- Etapa de finalización de la tarea estatal con las consiguientes fiestas, sacrificios, ceremonias rituales y reparto de regalos y mercedes.

Ahora bien, encuentro que en las tres etapas que consideré dentro del modelo descriptivo de toma de decisiones laborales, las asambleas fueron el lugar físico, público y simbólico en donde se consumó el consenso de las negociaciones y convenios de redistribución de los distintos poderes en juego en el Estado Inca de los siglos XV-XVI, según las tradiciones apuntadas por Betanzos.

- Por tanto, sostengo que hubo por lo menos tres tipos de asambleas en el ámbito del gobierno inca, que se referían a las relaciones laborales y prestaciones de mano de obra.

- Y que, a cada etapa dentro del proceso de toma de decisiones laborales le correspondió un tipo de asamblea en el ceno de la corte cuzqueña. 
A continuación describiré someramente cada tipo de asamblea.

1) El primer tipo de asamblea, fue en la que se confirmaban las decisiones acerca de qué tarea estatal realizar y en qué momento. Los encargados de decidir en ella fueron el Inca con los "Señores del Cuzco". (Evidentemente que por el tipo de relaciones que vimos que tenían los "Señores del Cuzco" con los "caciques provincianos", estos últimos debieron influir en tales decisiones).

2) El segundo tipo de asamblea, fue en donde se confirmaba cómo se haría la tarea y quiénes la llevarían a cabo. Fue la instancia del reparto de los trabajos y coordinación de la energía laborable. Los encargados de decidir en ella fueron los "Señores del Cuzco" conjuntamente con los "caciques provincianos". El control y dirección directo de los trabajadores fue de los poderes locales provinciales ("caciques", "principales", "mayordomos" y "maestros" en oficios), y no del poder central cuzqueño, que supervisaba y coordinaba las tareas con el nivel jerárquico de decisión de los "caciques provincianos".

3) El tercer tipo de asamblea, fue en donde se creaban y reafirmaban ritualmente las relaciones político laborales con los distintos grupos de poder que apoyaron la realización de la tarea estatal. Fue el momento de la redistribución pública y simbólica, en donde el Inca entregaba "dádivas y mercedes" a los "caciques provincianos". De esta manera, se acuatizaban los lazos políticos y de parentesco que hacian posibles futuros pactos laborales.

Una vez que construí un modelo descriptivo de toma de decisiones laborales, en donde diferencié tres etapas y tres tipos de asambleas, cabe preguntarme por la fijación calendárica de dicho proceso de toma de decisiones laborales y de dichas asambleas.

Ziólkowski en la obra anteriormente citada, aporta la hipótesis de que este tipo de obligaciones mutuas (las contribuciones de las prestaciones laborales aportadas por cada grupo de tributarios y la consiguiente redistribución), entre el Inca y los "caciques provincianos", nos pueden dar pistas para llegar a una cronología relativamente fidedigna de los procesos históricos acontecidos. (Ziółkowski 1996: 228).

De hecho sabemos que tanto el gobierno Inca como los grupos que prestaban contribuciones laborales compartían un mismo calendario solar; se estipulaban fechas exactas para celebración de las asambleas y la realización de los trabajos. (Betanzos 1987: 56/7 [1551: L I, cap. XII]; 1987: 100 [1551: L I, cap. XX]).

Incluso hay un capítulo de la crónica de Betanzos dedicado a la reorganización, 
por parte de Ynga Yupangue del calendario agrícola y ritual del Estado, capítulo denominado:

"Capítulo XV. Que trata de cómo Ynga Yupangue señaló el año e los meses y les puso nombre y de las grandes idolatrías que constituyó en las fiestas que ansi ordenó que se hiciesen en los tales meses e de cómo hizo relojes de sol por los cuales viesen los de la ciudad del Cuzco cuándo era tiempo de sembrar sus sementeras" (Betanzos 1987: 71 [1551: L I, cap. XV]).

Pero si bien los informantes de la tradición oral nos brindan datos sobre la utilización del calendario solar, no encontré informaciones que pueda relevar con respecto a la periodicidad y cronología de dichas asambleas, salvo el orden consecutivo de las tres etapas de planificación, realización y finalización, que ya apunté.

Evidentemente el pedido de las prestaciones de mano de obra por parte del Estado debió coordinar un calendario agrícola común que considerase tanto las necesidades del Estado como las necesidades de las etnias provincianas y debió compatibilizar la utilización de determinadas tecnologías agropecuarias.

Como ya sostuve anteriormente no pudo haberse llegado al nivel de reservas alimentarias, a la complejidad socio cultural y a la extensión territorial que alcanzó el Estado Inca en los siglos XV-XVI, sin la coordinación mencionada.

Debido a esta "laguna" en mis conocimientos actuales, dejo para futuras investigaciones, con la utilización de otras fuentes y otras tradiciones orales, determinar, en lo posible, la cronología y periodicidad de los procesos de toma de decisión laborales y de las asambleas incluidas en ellos.

\section{CONCLUSIONES}

Considero que he logrado describir en este trabajo, a la luz de la tradición oral relevada en la crónica de Betanzos, ciertas estructuras y modalidades de las relaciones laborales que se desarrollaron en el Estado Inca de los siglos XV-XVI, que dan cuenta de la reconstrucción de un fenómeno andino histórico pasado: las asambleas, ámbitos rituales, públicos y consensuados.

Por tanto, no pienso que lo que describen los informantes del cronista, en la "Suma y Narración de los Incas", sea meramente la descripción de recuerdos de decisiones importantes que dichos informantes quisieron resaltar o "adornos estilísticos" de la pluma de Betanzos, sino un protocolo minucioso de procedimientos en la toma de decisiones laborales, que dejan constancia de una institución estatal inca. 
Para finalizar, reitero que la fuente de información de que dispongo es una fuente que expresa la tradición oral de un linaje real cuzqueño en particular (el de Ynga Yupangue), y por ello el énfasis en cuanto a las funciones y relaciones laborales está puesto en el lado cuzqueño y en sus representantes. A pesar de ello creo haber probado con el análisis de los 57 ejemplos que consideré, que las relaciones laborales en el Estado Inca fueron, según esos mismos informantes, el resultado de negociaciones, acuerdos y pactos con los "caciques provincianos", y que la participación en las decisiones laborales de estos mismos "caciques provincianos" fue necesaria y efectiva junto con la de los "Señores del Cuzco".

Ahora bien, el desafio que se me presenta para un próximo ensayo es contrastar esta perspectiva de los poderes de la tradición oral cuzqueña, en donde el énfasis está puesto en el consenso, obtenido en las negociaciones laborales con los poderes provinciales, y la visión de los propios poderes provinciales, en donde probablemente la obtención de dicho consenso debió resultar más o menos conflictiva, más o menos beneficiosa para los mismos.

\section{GLOSARIO}

Aklla: mujer escogida reservada al Inca o al culto Solar.

Ayllu: linaje.

Chunka kamayuq: encargado local de diez jefes de familia.

Khipu: sistema numérico de cuerdas anudadas de distintos colores utilizado en los Andes como técnica de registro para relevar datos contables.

Kuraka: jefe étnico local de la comunidad andina.

Llaqta: aldea, que comprende un espacio territorial, un centro ceremonial y la población residente agrupada en linajes.

Llaqta kamayuq: encargado de la aldea.

Mita: trabajo entregado por las unidades domésticas, rotativo y anual, estatal y/o comunal Panakas: linajes reales incaicos.

Qumpi: tejidos finos andinos.

Runa: jefe de la unidad doméstica, con responsabilidad sobre ella, y con la obligación de los turnos rotativos de trabajo hacia el Estado y hacia la comunidad de pertenencia.

Waka: dioses, antepasados, ancestros andinos, lugar sagrado.

\section{BIBLIOGRAFÍA}

BETANZOS, Juan de

1987 (1551). Suma y narración de los Incas. Ediciones Atlas, Madrid. 
DOMÍNGUEZ FAURA, Nicanor

1998. Dos breves notas sobre el cronista Juan Díez de Betanzos. Revista Andina 16(1), Julio de 1998.

EARLS, John

1976. Evolución de la administración inca. En Andenes y camellones en el Perí andino. CONCYTEC, Lima.

1986. Experimentación agrícola en el Perú prehispánico y su factibilidad de reempleo. En Andenes y camellones en el Perú andino. CONCYTEC, Lima.

1991. Ecología y Agronomía en los Andes. HISBOL, La Paz.

GONZÁLEZ HOLGUÍN, Diego

1952 (1609). Vocabvlario de la lengva general de todo el Perí... Edición del Instituto de Historia, Imprenta Santa María, Lima.

MARTINEZ CERECEDA, José Luis

1995. Autoridades en los Andes, los atributos del Señor. Pontificia Universidad Católica del Perú, Fondo Editorial de 1995, Lima.

MURRA, John V.

1975. Formaciones económicas y políticas del mundo andino. IEP, Lima.

PÄRSSINEN, Martti

1992. Tawantinsuyu. The Inca State and Its Political Organization. SHS, Studia Historica 43, Helsinki.

PEASE, Franklin

1991. Los Incas. Pontificia Universidad Católica del Perú, Fondo Editorial de 1991, Lima.

1992. Perú: Hombre e Historia. Volumen II. Entre el siglo XVI y XVII. EDUBANCO. Lima.

RAMOS, Demetrio

1987. La prospección Incanista de Juan de Betanzos, a mediados del XVI: El carácter de sus trabajos y su apreciación de la infraestructura político-social. En Estudios preliminares de "Suma y narración de los Incas". Ediciones Atlas, Madrid.

STERNFELD, Gabriela

1998. Proyecto de tesis Doctoral: Organización laboral del Estado Inka: Las autoridades locales básicas.

SZEMIŃSKI, Jan

1998. ¿Es posible reconstruir forma y contenido de la tradición bistórica contada en quechua en base a su supuesta traducción al castellano? $0_{\circlearrowright}$ Cómo diferenciar entre tradiciones originales traducidas al castellano y tradiciones postcoloniales compuestas en castellano? Ponencia presentada en el Congreso Internacional de Etnohistoria, Jujuy.

ZIÓŁKOWSKI, MariusZ

1997. La guerra de los Wawqui. Los objetivos y los mecanismos de la rivalidad dentro de la élite inka, S. XV-XVI. Biblioteca ABYA - YALA 41, Quito.

ZUIDEMA, R. Tom

1991. La civilización inca en Cuzco. Fondo de Cultura Económica, México

1995. El sistema de ceques del Cuzco. La organización social de la capital de los Incas. Pontificia Universidad Católica del Perú, Fondo Editorial de 1995, Lima. 